University of Zurich

Department of Economics

Working Paper Series

ISSN 1664-7041 (print)

ISSN 1664-705X (online)

Working Paper No. 51

\title{
Wealth Inequality and the Optimal Level of Government Debt
}

Sigrid Röhrs and Christoph Winter

December 2011 


\title{
Wealth Inequality and the Optimal Level of Government Debt*
}

\author{
Sigrid Röhrs ${ }^{\dagger}$ and Christoph Winter ${ }^{\ddagger}$
}

February 15, 2011

\begin{abstract}
In this paper, we quantitatively analyze to what extent a benevolent government should issue debt in a model where households are subject to idiosyncratic productivity shocks, insurance markets are missing and borrowing is restricted. In this environment, issuing government bonds facilitates saving for self-insurance.

Despite this, we find that in a calibrated version of the model that is consistent with the skewed wealth and earnings distribution observable in the U.S., the government should buy private bonds, and not issue public debt in the long run. The reason is that in the U.S., a large fraction of the population has almost no wealth or is even in debt. The wealth-poor, however, do not profit from an increase in the interest rate following an increase in public debt. Instead, they gain from higher wages that result from a reduction in debt.

We show that even when the short run costs of higher capital taxation are taken into account, it still pays off to reduce government debt on overall. Moreover, we find that endogenizing household's borrowing constraints by assuming limited commitment leads to even higher asset levels being optimal in the long run.
\end{abstract}

Key words: Government Debt, Endogenous Borrowing Constraints, Incomplete Markets, Crowding Out

JEL classification: E2, H6, D52

*Acknowledgements: We would like to thank Alexander Bick, Timo Boppart, Nicola Fuchs-Schündeln, Wouter den Haan, John Hassler, Marcus Hagedorn, Kenneth Judd, Leo Kaas, Timothy Kehoe, Nobuhiro Kiyotaki, Felix Kübler, Alex Michaelides, Dirk Niepelt, Karl Schmedders, Kjetil Storesletten, Iván Werning participants of the seminar "Advances in Computational Economics and Finance" at the University of Zurich and especially Fabrizio Zilibotti for many useful comments. The paper was presented at the PhD Workshop on Dynamic Macroeconomics June 2010 in Strasbourg, at the Annual Meeting of the European Economic Association August 2010 in Glasgow, at the University of St.Gallen, at the University of Frankfurt, at the University of Fribourg and at the Study Center in Gerzensee. Sigrid would like to thank the University of Zurich for financial support (Forschungskredit Nr. 53210601). Financial support from the European Research Council (ERC Advanced Grant IPCDP-229883) is gratefully acknowledged. All remaining errors are our own.

${ }^{\dagger}$ University of Zurich, Institute for Empirical Research in Economics, Office MUB-H 501, Mühlebachstrasse 86, 8008 Zurich (Switzerland), +41 (044) 63455 71, sroehrs@iew.uzh.ch

${ }^{\ddagger}$ University of Zurich, Institute for Empirical Research in Economics, Office MUB-G405, Mühlebachstrasse 86, 8008 Zurich (Switzerland), +41(044)63452 66, chwinter@iew.uzh.ch 


\section{Introduction}

In this paper, we ask the following question: what is the optimal level of government debt in a world where insurance markets are incomplete, households are thus subject to uninsurable shocks to their labor income and borrowing is restricted?

We consider a model in the spirit of Aiyagari (1994) where households are subject to idiosyncratic shocks to their labor productivity and insurance markets are missing. Only one-period risk-free bonds are available for households to self-insure against income shocks. Bonds are issued by firms (as claims to physical capital) or by the government in the form of public debt. In the absence of aggregate risk, claims to physical capital and public debt are perfect substitutes. As noted by Albanesi (2008), issuing government bonds in such an environment might be an effective way to improve risk-sharing and aggregate welfare.

With the help of this model, we analyze quantitatively to what extent the U.S. government should issue debt. Perhaps surprisingly, we find that the optimal level of government debt is negative in the long run. In other words, our findings suggest that in a long run perspective the government should save and supply capital to the production sector instead of issuing bonds.

Our finding can be explained as follows. As it is well known from the seminal papers of Woodford (1990) and Aiyagari and McGrattan (1998) as well as more recently by Gomes, Michaelides, and Polkovnichenko $(2008,2010)$ issuing government bonds can have very different effects in an environment with incomplete markets compared to a setting where markets are complete. Heathcote (2005) makes a similar point with respect to fiscal policy in general. If borrowing constraints are binding, raising government debt crowds out private capital, even when taxes are lump-sum. In this case, households that face binding borrowing constraints will not increase their savings one-to-one in response to an increase in debt, and Ricardian Equivalence breaks down. This implies that the demand for private bonds will not meet the supply of private bonds issued by the firm. We say that public debt crowds out private capital, and therefore also production and output. As a result, the equilibrium interest rate that clears the private bond market will increase, and the marginal product of labor will decrease. Heathcote (2005), who studies tax reforms in a model with borrowing constraints, finds that this effect can be quantitatively important. Moreover, if taxation is distortionary instead of lump-sum, the negative effect of government debt on capital and output is even stronger, due to an inefficiently low supply of labor and capital. Clearly, both the crowding out of capital as well as the efficiency losses due to distortionary taxation reduce aggregate welfare.

In an world with incomplete markets, there are two additional effects how government debt can influence the well-being of households. Both channels work through the changes in the interest rate and the wage rate resulting from crowding out and distortionary taxation. First, a higher interest rate facilitates self-insurance of private households, since saving yields a higher return (Aiyagari and McGrattan, 1998). Put differently, government debt has an insurance effect because the price of the riskless production factor (capital) increases, while the price of the risky factor (labor) decreases (Davila et al., 2007; Gottardi, Kajii, and Nakajima, 2010). Second, government debt also affects the distribution of consumption via the composition of income, because households that receive capital income benefit and households that mainly rely on labor income lose. The insurance and the income composition channel might have counteracting effects on total welfare, since the households that profit the most 
from additional insurance are the consumption-poor, which also suffer the most from a decline in wages.

Our result suggests that the negative impact government debt has on welfare via efficiency losses and the income composition channel overrides the positive effect of additional insurance. Our conclusion that the government should optimally provide additional capital as a means of production instead of issuing debt stands thus in contrast to the view of Aiyagari (1995). In this seminal contribution, he emphasizes that the precautionary saving motive present in incomplete markets economies leads to an overaccumulation of capital compared to the complete market benchmark, suggesting that any government policy that reduces capital could be welfare improving. However, if one takes the fact that markets are incomplete as given, as we do here, a social planner could improve welfare by providing additional private capital. In this sense our finding is in line with the recent contributions of Davila et al. (2007) and Gottardi, Kajii, and Nakajima (2010). Both papers find that competitive equilibrium allocation of resources is constrained inefficient, and that there is in fact an underaccumulation of capital. Our paper contributes to this literature by showing that a benevolent government can increase aggregate welfare by accumulating assets and buying private bonds. This policy can - at least partly make up for the underaccumulation of assets in the private sector.

We show that our main result - namely that the government should hold assets instead of debt hinges on the fact that wealth and income in the United States are very unequally distributed across the population. Because households that are consumption-poor also hold no wealth or are even in debt, the positive insurance effect of government debt is weak in terms of aggregate welfare. This explains why we find substantial negative welfare effects of government debt, whereas Aiyagari and McGrattan (1998) and in particular Flodén (2001) conclude that the opposing effects almost cancel out, leading to only weak overall welfare effects of government debt. Compared to these authors, we explicitely target the high wealth and earnings inequality observed in the U.S. in our calibration procedure, following Castañeda, Díaz-Giménez, and Ríos-Rull (2003).

Looking explicitly at different wealth-groups in the population shows an even stronger effect for those individual groups. Paying back government debt and accumulate assets benefits in particular poor agents. The reason is that they depend primarily on wage income. For this group, the positive effects of crowding in (more private capital) in form of higher wages thus outweigh the negative effects of a lower interest rate.

Another important contribution of our paper is that we are also able to show that the long-run welfare gains that can be achieved by reducing government debt with respect to the status quo can outweigh the short-run losses that occur over the transition, as long as the government uses the right set of policy instruments. We propose the policy to reduce government debt by taxing capital highly in one period, and then reduce either capital taxes or labor taxes from then onwards. This policy is inspired by Greulich and Marcet (2008), who show theoretically that in a model with wealth heterogeneity but without borrowing constraints it is Pareto-optimal to leave capital income taxes high in the short run, but reduce them to zero in the long run.

In the standard incomplete market setting, borrowing constraints are exogenous and thus invariant to public policy. However, there are good reasons to believe that financial market conditions that determine borrowing restrictions also react to policy changes. Therefore we endogenize borrowing limits by assuming that households can default on their financial liabilities. Upon default, households are 
excluded from future borrowing and lending forever. As in Zhang (1997), Ábrahám and Cárceles-Poveda (2008) and Ábrahám and Cárceles-Poveda (2010), borrowing constraints are set such that households are indifferent between defaulting and participating in financial markets, so that there is no default in equilibrium. If the government accumulates assets, the resulting fall in the interest rate makes default less attractive, as a lower interest rate makes it easier for households to service their debt. As a consequence, borrowing limits become laxer, and the fraction of the population that is in debt increases. We find that this effect causes the optimal long run level of government assets to be even higher compared to the case when borrowing limits are exogenous.

In line with Attanasio and Ríos-Rull (2000), Ábrahám and Cárceles-Poveda (2008), Ábrahám and Cárceles-Poveda (2010) and Krueger and Perri (2010) our results underline the importance of endogenizing the borrowing limit for analyzing the impact of public policy.

Our paper is related to the recent literature analyzing the macroeconomic consequences of the recent financial crisis through the lens of incomplete markets models. Gomes, Michaelides, and Polkovnichenko (2010) focus on quantifying the cost of the increase in government debt during the episode of the 'bailout'. For their analysis, they look at incomplete market models with aggregate uncertainty. They do not perform a welfare analysis. Oh and Reis (2010) argue that the fiscal rescue package after the financial crisis mainly resulted in an increase in targeted transfers. Therefore they analyze the impact of targeted transfers on aggregate economic activity in an incomplete markets model with sticky prices. Interestingly, they also point out that in the United States between 2007 and 2009, public debt increased but private debt fell. This is consistent with our extended version of the model, where a tightening of private borrowing conditions results from higher interest rates caused by high public debt. In general however, we view our work with its focus on government debt and welfare analysis as complementary to those recent papers.

The remainder of the paper is structured as follows. We present the baseline model in the next section. In section 3, we discuss the role of borrowing constraints by showing that Ricardian equivalence still holds under incomplete markets, lump sum taxes and without borrowing constraints. In section 4 we discuss the calibration of the model. Section 5 shows the quantitative results. Section 6 concludes.

\section{The Baseline Model}

The economy we consider is a neoclassical growth model with incomplete markets where households face uninsurable income shocks, as in Aiyagari (1994). Only one-period risk-free bonds are available for households to self-insure against income shocks. Bonds are provided by either firms, in which case they can be interpreted as claims to physical capital $k_{t}$, or by the government, which issues government bonds $b_{t}$ (as in Aiyagari and McGrattan, 1998; or Flodén, 2001). As we assume no aggregate risk, claims on physical capital and government bonds are perfect substitutes and thus yield the same return $r_{t} .{ }^{1}$ In the following, we present the household sector, the firm sector and the government sector in greater detail.

\footnotetext{
${ }^{1}$ In Gomes, Michaelides, and Polkovnichenko (2008, 2010), government bonds and private capital are imperfect substitutes due to aggregate uncertainty.
} 


\subsection{Household sector}

The economy is populated by a continuum of ex-ante identical, infinitely lived households with total mass of one. Households maximize their expected utility by making a series of consumption, leisure and savings choices subject to a budget constraint and a borrowing limit on assets. In period $t=0$, before any uncertainty has realized, their expected utility is given by

$$
U\left(\left\{c_{t}, l_{t}\right\}_{t=1,2, \ldots},\right)=E_{0} \sum_{t=0}^{\infty} \beta^{t} u\left(c_{t}, l_{t}\right)
$$

where $\beta$ is the subjective discount factor. The per-period utility function, $u($.$) , is assumed to be$ strictly increasing, strictly concave and continuously differentiable. Additionally the first derivative is assumed to satisfy the following limiting (Inada) conditions:

$$
\begin{aligned}
\lim _{c \rightarrow 0} u_{c}(c, l) & =\infty, \lim _{c \rightarrow \infty} u_{c}(c, l)=0 \\
\lim _{l \rightarrow 0} u_{l}(c, l) & =\infty
\end{aligned}
$$

The idiosyncratic shocks to household productivity, $\epsilon_{t}$, follow a Markov process with transition matrix $\pi\left(\epsilon^{\prime} \mid \epsilon\right)$.

A household thus faces the following per-period budget constraint:

$$
c_{t}+a_{t+1}=y_{t}
$$

where $a_{t+1}=k_{t+1}+b_{t+1}$ denotes the sum of the claims on physical capital and government bonds in $t+1$ bought by the household in period $t$ and $y_{t}$ is the agent's individual (after-tax) income. The households asset choice is restricted by an ad-hoc borrowing limit:

$$
a_{t+1} \geq \underline{a}
$$

Let $\theta(a, \epsilon)$ denote the joint distribution of asset holdings and productivity shocks. Let $\Gamma$ denote the transition function which maps the current distribution $\theta_{t}(.,$.$) into a new distribution \theta_{t+1}(.,$.$) :$

$$
\theta_{t+1}\left(a_{t+1}, \epsilon_{t+1}\right)=\Gamma\left[\theta_{t}\left(a_{t}, \epsilon_{t}\right)\right]
$$

The government can tax labor income at some proportional tax rate, $\tau_{l, t}$, as well as financial income at some proportional tax rate, $\tau_{a, t}$, and can redistribute income via lump sum transfers, $\chi_{t}$. We assume that only non-negative financial income is taxed or in other words there are no proportional subsidies in the face of financial losses. More precisely, we define the tax on financial income $\tau_{a}$, as follows:

$$
\tau_{a, t}\left(a_{t}\right)=\left\{\begin{array}{c}
\bar{\tau}_{a, t} \text { if } a_{t} \geq 0 \\
0 \text { if } a_{t}<0
\end{array}\right.
$$

The after-tax interest rate is therefore given by $\bar{r}_{t}=\left(1-\tau_{a, t}\left(a_{t}\right)\right) r_{t}$. The after-tax wage rate is given by $\bar{w}_{t}=\left(1-\tau_{l, t}\right) w_{t}$ where $w_{t}$ is the price of labor in the economy. After-tax income is thus given by:

$$
y_{t}=\bar{w}_{t} \epsilon_{t}\left(1-l_{t}\right)+\left(1+\bar{r}_{t}\right) a_{t}+\chi_{t}
$$


The optimization problem of the household in recursive formulation looks as follows (see the Appendix for the derivation of a detrended formulation):

$$
\begin{aligned}
W(a, \epsilon ; \theta) & =\max _{c, l, a^{\prime}}\left\{u(c, l)+\beta \sum_{\epsilon^{\prime}} \pi\left(\epsilon^{\prime} \mid \epsilon\right) W\left(a^{\prime}, \epsilon^{\prime} ; \theta^{\prime}\right)\right\} \\
\text { s.t. } c+a^{\prime} & =\bar{w} \epsilon(1-l)+(1+\bar{r}) a+\chi \\
a^{\prime} & \geq \underline{a} \\
\theta^{\prime} & =\Gamma[\theta]
\end{aligned}
$$

\section{$2.2 \quad$ Welfare measure}

To answer the normative question of which level of government debt would be optimal, we have to define a welfare criterion. Following the previous literature as for example, Aiyagari and McGrattan (1998) and Flodén (2001), we use as a welfare criterion the aggregate optimal value function:

$$
\Omega=\int W(a, \epsilon ; \theta) d \theta(a, \epsilon)
$$

This criterion can either be interpreted as (1) a utilitarian social welfare function where every individual has the same weight for the planner, (2) a steady-state ex ante welfare of an average consumer before realizing income shocks or initial asset holdings or (3) the probability limit of the utility of a infinitely lived dynasty where households utilities are altruistically linked to each other (for more details see Aiyagari and McGrattan, 1998).

Because it is easier to interpret, we compute the average consumption equivalent change in welfare. A more precise definition is given in the Appendix.

\subsection{Production sector}

The production sector consists of a representative firm which uses capital, $K_{t}$, and labor, $L_{t}$, to produce output, $Y_{t}$. :

$$
Y_{t}=F\left(K_{t}, X_{t} L_{t}\right)
$$

where $X_{t}$ denotes exogenous labor-augmenting technological progress. ${ }^{2}$ This technology is assumed to grow exogenously at a constant rate $X_{t+1}=(1+g) X_{t}$. For simplicity we normalize initial technology to $X_{0}=1$, such that:

$$
X_{t}=(1+g)^{t}
$$

The production function $F(.,$.$) is assumed to have standard properties. The firm has to rent capital$ and labor from the owners at prices $w_{t}($ wage $=$ price of labor $)$ and $r_{K t}($ rental rate $=$ price of capital $)$. Thus competitive factor markets and profit maximizing firms imply the following prices of labor and capital:

$$
\begin{aligned}
w_{t} & =F_{L}\left(K_{t}, X_{t} L_{t}\right) \\
r_{t} & =F_{K}\left(K_{t}, X_{t} L_{t}\right)-\delta
\end{aligned}
$$

\footnotetext{
${ }^{2}$ The presence of technological progress matters for the calibration of the discount factor. Without growth one would need a higher discount factor in the model to produce an realistic interest rate. The discount factor plays an important role for assessing the optimal value of government debt (Aiyagari and McGrattan (1998) and Flodén (2001)).
} 
where $r_{t}$ is the rate of return net of depreciation. In equilibrium this rate of return has to be equal across all assets and thus determines the "interest rate" on assets.

\subsection{Government sector}

The government has to finance a fixed amount of government spending $G$ and the total transfers to households, $T R$ by issuing new government bonds, $B_{t+1}$ and levying taxes on positive asset and labor income. Furthermore it also has to pay back bonds from the last period, $B_{t}$ and pay interest on them, $r_{t} B_{t}$. The government budget constraint is thus given by:

$$
G+r_{t} B_{t}+T R=B_{t+1}-B_{t}+\tau_{l} w_{t} L_{t}+\bar{\tau}_{a} r_{t} \widehat{A}_{t}
$$

where $\widehat{A}_{t} \geq A_{t}$ is the tax base for the asset income tax. As explained above taxes are only levied on positive financial income (no proportional transfers from the government for indebted people) and thus the tax base is defined as:

$$
\widehat{A}_{t}=\int_{a_{t} \geq 0} a_{t} d \theta\left(\epsilon_{t}, a_{t}\right)
$$

Aggregate transfers have to equal the sum of all individual transfers:

$$
\int \chi d \theta\left(\epsilon_{t}, a_{t}\right)=T R
$$

\subsection{Recursive competitive equilibrium}

Using the characterization of the three sectors we can now define the recursive competitive equilibrium.

Definition 1. Given a transition matrix $\pi$, a certain sequence of government bond issues $\left\{B_{t}\right\}_{t=0}^{\infty}$, the time invariant level of government expenditures $G$, a certain sequence of capital income taxes $\left\{\tau_{a}\left(a_{t}\right)\right\}_{t=0}^{\infty}$, a certain sequence of labor income taxes $\left\{\tau_{l, t}\right\}_{t=0}^{\infty}$ and an initial distribution of the idiosyncratic productivity shocks and of the asset holdings $\theta_{0}\left(\epsilon_{0}, a_{0}\right)$ a recursive competitive equilibrium is defined by a law of motion $\Gamma$, factor prices $\left(r_{t}, w_{t}\right)=\left(r\left(K_{t}\right), w\left(K_{t}\right)\right)$, the value function $W=W(\theta, a, \epsilon)$ and policy functions $\left(c, a^{\prime}\right)=(\gamma(\theta, a, \epsilon), \zeta(\theta, a, \epsilon))$ such that

1. Households' utility maximization problem is defined in equation (2).

2. Competitive firm maximize profits, such that factor prices are given by (3) and (4).

3. The government budget constraint as defined in equation (5) holds.

4. Factor and goods markets have to clear:

- Labor market clearing:

$$
N_{t}=\int \epsilon_{t}\left(1-l_{t}\right) d \theta\left(\epsilon_{t}, a_{t}\right)=L_{t}
$$

- Asset market clearing:

$$
A_{t+1}=\int a_{t+1} d \theta\left(\epsilon_{t}, a_{t}\right)=K_{t+1}+B_{t+1}
$$


- Goods market clearing:

$$
\int c_{t} d \theta\left(\epsilon_{t}, a_{t}\right)+G+I_{t}=F\left(K_{t}, X_{t} L_{t}\right)
$$

where investment, $I_{t}$ is the sum of private investment and public investment:

$$
I_{t} \equiv K_{t+1}-(1-\delta) K_{t}+B_{t+1}-\left(1+r_{t}\right) B_{t}
$$

5. Rational expectations of households about the law of motion of the distribution of shocks and asset holdings, $\Gamma$ reflect the true law of motion, as defined in (1).

\section{Ricardian equivalence and the role of the borrowing limit}

The assumption that households face binding borrowing constraints is central to the effect of government debt on the economy that we emphasize in this paper. It is a well known result that under complete markets and lump sum taxation government debt is neutral because agents foresee future tax changes and adapt their savings behaviour accordingly. But also under incomplete markets (and lump sum taxes) Ricardian equivalence holds, if there are no "ad hoc" borrowing limits. ${ }^{3}$ Thus it is not the market incompleteness per se, but rather the combination of market incompleteness and borrowing constraints that leads to an effect of government debt on the economy. Thus one has to distinguish clearly between effects arising due to the presence of borrowing constraints (in other words "crowding out") and effects due to tax distortions. Heathcote (2005) makes a similar point in a related contribution. ${ }^{4}$ The goal of this section is to clearly show this point analytically. More precisely, we will show that government debt is neutral for the case of natural borrowing limits and explicitely make clear why "ad hoc" borrowing limits lead to non-neutrality of government debt.

In the incomplete markets model described above the maximization problem of the household, if there are no "ad hoc" borrowing limits can be characterized by the following Bellman equation (in recursive notation):

$$
\begin{array}{r}
W(a, \epsilon ; \theta)=\max _{l, a^{\prime}, c}\left\{u(c, l)+\beta \sum_{\epsilon^{\prime}} \pi\left(\epsilon^{\prime} \mid \epsilon\right) W\left(a^{\prime}, \epsilon^{\prime} ; \theta^{\prime}\right)\right\} \\
\text { s.t. } \bar{w} \epsilon(1-l)+(1+\bar{r}) a+\chi=a^{\prime}+c \\
c \geq 0
\end{array}
$$

Suppose the government issues supplementary debt $\Delta b$ and redistributes the proceeds as a supplementary transfer, such that $\chi_{n e w}=\chi+\Delta b$. Furthermore suppose that the additional taxes necessary to pay the interest payments in future periods will be lump sum. It is easy to show that this policy doesn't affect the permanent income of an agent. Although he gets a transfer now, he has to pay higher taxes in the future whose present value is equal to the transfer received. Therefore to smooth consumption

\footnotetext{
${ }^{3}$ In this case there is still a so called natural borrowing limit arising from the fact that consumption must be positive (see also Aiyagari (1994)).

${ }^{4}$ Heathcote (2005) analyzes the quantitative short run effects of changes in the timing of proportional income taxes in heterogeneous agent economies with incomplete markets. He also distinguishes between effects via tax distortions and effects arising due to the presence of borrowing constraints.
} 
the household can simply save $a_{\text {new }}^{\prime *}=a^{\prime *}+\Delta b$, where $a^{\prime *}$ denotes the optimal savings without the supplementary debt issuance. This will leave the household's budget in the period of the issuance of government debt unaffected as the additional debt cancels out:

$$
\begin{aligned}
c+a_{\text {new }}^{\prime *} & =\bar{w} \epsilon(1-l)+(1+\bar{r}) a+\chi_{\text {new }} \\
c+a^{\prime *}+\Delta b & =\bar{w} \epsilon(1-l)+(1+\bar{r}) a+\chi+\Delta b
\end{aligned}
$$

In future periods his budget is also unaffected as the additional income from savings can be used to pay the additional lump sum tax. (Note that the necessary additional lump sum tax is reduced by the higher income from asset income taxation $T_{\text {new }}^{\prime}=r^{\prime} \Delta b-\tau_{a}^{\prime} r^{\prime} \Delta b=\bar{r}^{\prime} \Delta b$ ):

$$
\begin{aligned}
c^{\prime}+a_{\text {new }}^{\prime \prime *}+T_{\text {new }}^{\prime} & =\bar{w}^{\prime} \epsilon^{\prime}\left(1-l^{\prime}\right)+\left(1+\bar{r}^{\prime}\right) a_{\text {new }}^{\prime *}+\chi \\
c^{\prime}+\left(a^{\prime \prime *}+\Delta b\right)+\bar{r}^{\prime} \Delta b & =\bar{w}^{\prime} \epsilon^{\prime}\left(1-l^{\prime}\right)+\left(1+\bar{r}^{\prime}\right)\left(a^{\prime *}+\Delta b\right)+\chi
\end{aligned}
$$

Thus the optimal path of consumption and leisure of the household remains unaffected by the policy. The demand for assets is increased exactly by the amount of government debt issues such that firms face the same remaining demand for their assets as before. As a consequence the interest rate and wage rate in the economy will remain the same. Government debt is neutral.

Result. Under incomplete markets, lump sum taxes, when households face no borrowing constraints, government debt is neutral.

Under an "ad hoc" borrowing constraint however the households for which the constraint binds do not save optimally but rather $a^{\prime}=\underline{a}$. Those households will thus not adapt their savings by adding

the additional government debt $a_{\text {new }}^{\prime}<\underline{a}+\Delta b$, because they can improve their consumption path (get nearer to the optimum) by consuming more in the period, when they are borrowing constrained and obtain the transfer. Intuitively, as there is the chance to obtain a higher income shock they might not be borrowing constrained anymore in the future. Thus they are more in need of funds today than tomorrow and use the transfer to "relax" their borrowing constraint. Therefore the aggregate demand for assets does not increase by as much as the new debt issues. The remaining demand for assets is lower and as a consequence capital is more expensive for firms. The interest rate in the economy will increase and the wage rate will decrease. Government debt is not neutral anymore. A more formal derivation of the results of this section is given in the Appendix.

In this section, we have shown that in our model binding borrowing constraints are a precondition for government debt to have non-trivial macroeconomic effects other than through accompanying changes in taxation. Given this important role of borrowing constraints we analyze the case where borrowing constraints are endogenous to public policy in the next section.

\section{An extension: endogenizing the borrowing limit}

So far, we have assumed that borrowing limits are exogenous and thus invariant to public policy. This does not necessarily need to be the case. In this section, we follow Zhang (1997), Alvarez and Jermann (2000), Kehoe and Levine (2001), Krueger and Perri (2006) and Ábrahám and Cárceles-Poveda (2010) who endogenously generate borrowing limits by assuming that households cannot commit to honor their 
debt contracts. In a related contribution, Ábrahám and Cárceles-Poveda (2008) show that endogenizing borrowing limits matters in an environment with incomplete markets for the optimal mix of capital and labor taxes.

In line with the literature on limited commitment, we assume that if households default, they are excluded from future borrowing and lending (autarky). The value of autarky can be expressed as follows:

$$
\begin{aligned}
V(\epsilon ; \theta) & =\max _{c^{\text {aut }}, l^{\text {aut }}}\left\{u\left(c^{\text {aut }}, l^{\text {aut }}\right)+\beta \sum_{\epsilon^{\prime}} \pi\left(\epsilon^{\prime} \mid \epsilon\right) V\left(\epsilon^{\prime} ; \theta^{\prime}\right)\right\} \\
\text { s.t. } c^{\text {aut }} & =(1+\lambda) \bar{w} \epsilon\left(1-l^{\text {aut }}\right)+\chi \\
\theta^{\prime} & =\Gamma[\theta]
\end{aligned}
$$

where $\lambda$ is a parameter describing a consumption gain (if $\lambda>0$ ), which translates into a utility gain, resulting in autarky. $\lambda$ captures, in reduced form, the differences between default regulation in reality and in our model. For example, a $\lambda>0$ could arise because in reality, exclusion from financial markets is temporary only, while exclusion is permanent in our model. ${ }^{5}$ We calibrate the value of $\lambda$ to match the number of people in debt. ${ }^{6}$

For households that have not defaulted yet, the optimization problem can be stated as follows:

$$
\begin{aligned}
W(a, \epsilon ; \theta) & =\max _{c, l, a^{\prime}}\left\{u(c, l)+\beta \sum_{\epsilon^{\prime}} \pi\left(\epsilon^{\prime} \mid \epsilon\right) W\left(a^{\prime}, \epsilon^{\prime} ; \theta^{\prime}\right)\right\} \\
\text { s.t. } c+a^{\prime} & =\bar{w} \epsilon(1-l)+(1+\bar{r}) a+\chi \\
a^{\prime} & \geq \xi(\epsilon ; \theta) \text { for all } \epsilon^{\prime} \mid \epsilon \text { with } \pi\left(\epsilon^{\prime} \mid \epsilon\right)>0 \\
\theta^{\prime} & =\Gamma[\theta]
\end{aligned}
$$

It is the same problem as problem 2 above, except for the fact that the household's borrowing limit $\xi$ is now a function of the distribution of assets $(\theta)$ and the realization of the income shock $\epsilon$.

More precisely, the borrowing limit is defined as follows:

$$
\begin{aligned}
& \underline{a}(\epsilon ; \theta)=\{\underline{a}: W(a=\underline{a}, \epsilon ; \theta)=V(a=0, \epsilon ; \theta)\} \\
& \xi(\epsilon ; \theta) \equiv \sup _{\epsilon^{\prime}: \Pi\left(\epsilon^{\prime} \mid \epsilon\right)>0}\left\{\underline{a}\left(\epsilon^{\prime} ; \Gamma(\theta)\right)\right\}
\end{aligned}
$$

We impose that the borrowing limits in equilibrium are set such that there is no default. ${ }^{7}$ The recursive competitive equilibrium in this extended model is thus similar to the one stated in the previous section, with an additional no-default condition.

Definition 2. A recursive competitive equilibrium with endogenous borrowing limits is defined as a recursive competitive equilibrium as defined by Definition 1, where additionally

\footnotetext{
${ }^{5}$ Assuming instead a temporary exclusion from financial markets would make the model more complicated and does not yield any qualitative value added to the analysis.

${ }^{6}$ There may also be additional costs related to default (e.g. social stigma) which are not modeled. This would make $\lambda$ smaller. In the calibration section, we find that for our setting to be able to match the number of people in debt we need $\lambda>0$.

${ }^{7}$ The general mechanism - that borrowing conditions are tighter (looser) when the interest rate is higher (lower) - would also hold if we allowed for borrowing in equilibrium. As our aim is to model the endogenous reaction of the borrowing conditions and not the default behaviour of households we thus assume a model of limited commitment with no default in equilibrium. See Livshits, MacGee, and Tertilt (2007) and Chatterjee et al. (2007) for a discussion of U.S. bankruptcy laws and a quantitative model of consumer default.
} 
- Borrowing limits are set such there is no default as given by equation (7).

Ábrahám and Cárceles-Poveda (2010) show that if the period utility function is unbounded below, then equation (7) defines a unique and finite default threshold. They also show that the default threshold on individual capital holdings is non-positive. Intuitively, the borrowing limit, denoted by $\underline{a}$, is defined such that the value of being in autarky is just equal to the value of keeping the debt and staying in the market, if a household is actually on the borrowing limit. Or in other words the borrowing limit is the lowest possible asset holdings of an agent so that he still prefers holding on to the debt contract and staying in the market rather than not repaying the debt but being excluded. Depending on the income state, $\epsilon$, that realizes we will have a different borrowing limit. ${ }^{8}$

\section{Calibration}

As a benchmark, we calibrate our model with endogenous labor supply to the long run average of the U.S. economy.

\subsection{Utility Function, Production Function and Taxes}

We assume that preferences can be represented by a constant relative risk aversion utility function:

$$
u(c)=\frac{\left(c^{\eta} l^{1-\eta}\right)^{1-\mu}}{1-\mu}
$$

We set $\mu$, the coefficient of relative risk aversion, to 2 in our benchmark calibration, which is well in the range commonly chosen in the literature (between 1 and 3 ).

We also assume a Cobb-Douglas production function:

$$
F(K, X L)=K^{\alpha}(X L)^{1-\alpha}
$$

As already mentioned above, we normalized initial technology to $X_{0}=1$, such that $X_{t}=(1+g)^{t}$. The parameter $\alpha$ of the production function is set to target a labor share of 0.7 . The discount factor $\beta$ is set to target an asset-output ratio of 3.1 (cf. Cooley and Prescott (1995) or Ábrahám and Cárceles-Poveda (2010)). The labor elasticity $\eta$ is set to target an average labor supply of 0.3 . The depreciation rate is set to target an investment share of around 20 percent, which we estimate from the Penn World Tables. We take that annual depreciation rate $\delta$ to be 7 percent (see also Trabandt and Uhlig (2009)). Table 1 shows the values of the parameters and the targets to which they are calibrated.

The fiscal policy parameters are set as found by Trabandt and Uhlig (2009), which are similar to the ones found in Mendoza, Razin, and Tesar (1994) (see Table 2).

\footnotetext{
${ }^{8}$ Ábrahám and Cárceles-Poveda (2010) also show that the same borrowing limits would result by assuming perfectly competitive financial intermediaries. The "effective" borrowing limit that financial intermediaries will impose one period in advance, denoted by $\xi$, is chosen such that if the worst possible state (given the state today) occurs tomorrow the household will still not default. Thus they will choose the tightest of the possible borrowing limits as "effective" borrowing limit. Note that some state tomorrow could occur with zero probability given a particular state today. In this case, the associated borrowing limits can be neglected. As we will see later for our calibration, as it is possible to reach the lowest income state from any other previous state, there is thus only one relevant borrowing limit.
} 
Table 1: Targeted Parameter Values

\begin{tabular}{lrlrr}
\hline \hline \multicolumn{1}{c}{ Parameter } & Value & \multicolumn{1}{c}{ Target } & Data & Model \\
\hline & & & & \\
Capital's share, $\alpha$ & 0.3 & Labor share of output & 0.7 & 0.7 \\
Discount factor, $\beta$ & 0.9576 & Capital to output ratio & 3.1 & 3.1003 \\
Labor supply elasticity, $\eta$ & 0.3092 & Average labor supply & 0.3 & 0.30001 \\
Depreciation rate, $\delta$ & 0.07 & Investment share & 0.225 & 0.19 \\
Growth rate, $g$ & 0.02 & Average output growth & 0.02 & 0.02 \\
Autarky value, $\lambda$ & 0.083 & \% of HH with no assets or debt & 0.24 & 0.2473 \\
\hline \hline
\end{tabular}

Table 2: Parameter Values taken

from the Literature

\begin{tabular}{lr}
\hline \hline \multicolumn{1}{c}{ Parameter } & Value \\
\hline & \\
Debt to GDP ratio, $b$ & 0.670 \\
Labor tax, $\tau^{l}$ & 0.28 \\
Capital tax, $\tau^{k}$ & 0.36 \\
Transfers, $\chi$ & 0.083 \\
\hline \hline
\end{tabular}

\section{$5.2 \quad$ Income process}

We follow Castañeda, Díaz-Giménez, and Ríos-Rull (2003) by calibrating our model to the Lorenz curves of U.S. earnings and wealth as reported by the 2007 Survey of Consumer Finances (SCF). This is in contrast to the previous literature, where the earnings process was measured directly from the data. We choose this different procedure because it allows us to find an income process that is consistent with both the aggregate and the distributional aspects of the data on earnings and wealth (Castañeda, Díaz-Giménez, and Ríos-Rull (2003)). A desirable feature is that such an income process produces a sufficiently large amount of wealth accumulation by earnings-rich households to explain the high crosssectional inequality in wealth holdings seen in the data. Since we do not model housing, we define wealth as net financial assets excluding housing and other real assets (see also Ábrahám and Cárceles-Poveda (2010)). Earnings are defined in a way to be as close as possible to the concept of earnings in the model, i.e. labor earnings such as wages and salaries plus a fraction of business income before taxes and without government transfers (for a more detailed definition see Díaz-Gímenez, Quadrini, and Ríos-Rull (1997)). Note that we have to specify a vector of 4 income states and a $4 x 4$ transition matrix, which after normalization of the vector of income states leaves us with 15 targets to specify. Notice that this is much less than the actual number of potential targets that we could pick. Instead of targeting 15 specific points, we searched for a set of parameter values such that the Lorenz curves of earnings and wealth generated by the model are similar to the ones observed in the data. As an illustration how close our calibration achieves in matching the data we report the quintiles of the wealth distribution and the earnings distribution in Table 3 . 
More precisely, we find the following vector of income states:

$$
s=\{0.055,0.551,1.195,7.351\}
$$

It should be noted that the highest income state is more than 130 times as high as the lowest income state.

Table 3: Distributional properties at benchmark stationary economy

\begin{tabular}{lrrrrrr}
\hline \hline & Q1 & Q2 & Q3 & Q4 & Q5 & \% with assets $\leq 0$ \\
\hline Dealth (financial assets) \\
Benchmark Calibration & $-1.57 \%$ & $0.88 \%$ & $3.92 \%$ & $7.23 \%$ & $89.54 \%$ & $24.00 \%$ \\
Model fitted to AR(1) & $3.24 \%$ & $10.07 \%$ & $16.96 \%$ & $25.71 \%$ & $44.03 \%$ & $24.73 \%$ \\
\hline \multicolumn{7}{c}{ Earnings } \\
\hline Data & $-0.40 \%$ & $3.19 \%$ & $12.49 \%$ & $23.33 \%$ & $61.39 \%$ \\
Benchmark Calibration & $0.00 \%$ & $2.38 \%$ & $12.58 \%$ & $22.73 \%$ & $62.31 \%$ \\
Model fitted to AR(1) & $1.21 \%$ & $9.70 \%$ & $16.18 \%$ & $26.85 \%$ & $46.07 \%$ & \\
\hline \hline
\end{tabular}

* Quintiles (Q1-Q5) denote wealth (resp. earnings) of a group in percent of total wealth (resp. earnings).

** Last column denotes percent of population with no or negative assets.

Furthermore, we get the following transition matrix for the income states:

$$
\Pi=\left[\begin{array}{llll}
0.940 & 0.040 & 0.020 & 0.000 \\
0.034 & 0.816 & 0.150 & 0.000 \\
0.001 & 0.080 & 0.908 & 0.012 \\
0.100 & 0.015 & 0.060 & 0.825
\end{array}\right]
$$

As can be seen from the transition matrix, there is a 10 percent probability of moving from the highest income state today to the lowest income state tomorrow. This generates a strong saving motive for income-rich households, leading to the high degree of wealth inequality that we also observe in the data. The same mechanism is also present in the transition matrix found by Castañeda, Díaz-Giménez, and Ríos-Rull (2003).

In the rows labelled "Model fitted to $\mathrm{AR}(1)$ "in table 3, we report the earnings and wealth inequality that would result if the earnings states and the transition matrix where fitted to replicate an $\mathrm{AR}(1)$ process with persistence $\rho=0.6$ and variance $\sigma=0.3$ (the values used by Aiyagari and McGrattan (1998) in their benchmark specification). It is important to notice that this method does not generate the degree of wealth and earnings inequality that we observe in the data.

\subsection{Borrowing limits}

We calibrate the ad-hoc borrowing limit to match the percentage of households with negative or zero financial assets in the $2007 \mathrm{SCF}$ (24 percent). We find a borrowing limit of $\underline{a}=-0.3$. 
In the extension of the model with limited commitment we can generate this borrowing limit endogenously by setting the parameter defining utility in the autarky state to $\lambda=0.083$.

Recall that $\lambda>0$ can be interpreted as a relaxation of the autarky state, which suggests that our modelling of autarky is "too harsh" with respect to the data.

\section{Results}

We are now ready to compute the optimal amount of government debt with the help of our quantitative model. In the first section, we focus on the long run consequences of government debt on welfare. That is, we compare the aggregate welfare of stationary equilibria that are associated with different levels of government debt, ignoring the welfare effects that arise along the transition between different stationary equilibria. This allows us to compare our results with previous contributions that analyzed the optimal level of government debt by comparing stationary equilibria as well (see e.g. Aiyagari and McGrattan (1998) and Flodén (2001)). Second, we believe that this is a useful excercise to gain intuition about how government debt can affect welfare in general. In section 6.3 , we also include the transition path into our welfare calculations.

\subsection{Long run average welfare}

When markets are incomplete, an increase in government debt has positive and negative effects on aggregate welfare. In this section, we use our calibrated model to compute the net effect of these counteracting effects.

Remember that due to the presence of borrowing constrained agents savings will not be increased by the amount of additional government debt, but less, such that the bond price decreases or equivalently the interest increases. This implies crowding out of private capital and thus as firms produce less and need less labor as a consequence, a lower wage rate. The reverse happens when government debt is reduced (lower interest rate, higher wage rate). Additionally long run taxes change and affect welfare. For convenience, we now summarize the three main welfare effects of government debt in our framework. Consider for simplicity an increase in government debt (generally the reverse will hold true for a decrease) $:^{9}$

1. Level effect: As discussed above government debt leads to crowding out of private capital. If the capital stock in the benchmark economy is too low with respect to its efficient level, this crowding out leads to lower welfare. The behaviour of tax rates is non-monotonic, as will be discussed below. The level welfare effect of government debt through taxes depends if disposable income is higher or lower as a consequence.

2. Insurance effect: If the interest rate increases and the wage rate falls, the uncertain component of income, namely labor income, is reduced relative to the certain component (capital income). This

\footnotetext{
${ }^{9}$ Our labelling of the different effects follows Flodén (2001). He distinguishes between a "level" effect, an "uncertainty" effect and an "inequality" effect. We chose to label the redistributive effect "income composition effect", because we would like to capture how the redistribution arises, namely because of the different compositions of income between households in this model.
} 
leads to less uncertainty of consumption and thus to welfare gains for households from an ex ante perspective.

3. Income composition effect: As the interest rate rises relative to the wage rate, wealth-rich households gain compared to wealth-poor households, because the latter depend more on labor income. Because the wealth-poor are also the consumption-poor, this leads to an aggregate welfare loss since marginal utility is higher for households with low levels of consumption.

Figure 1 shows the average consumption equivalent change in welfare over the different stationary equilibria.

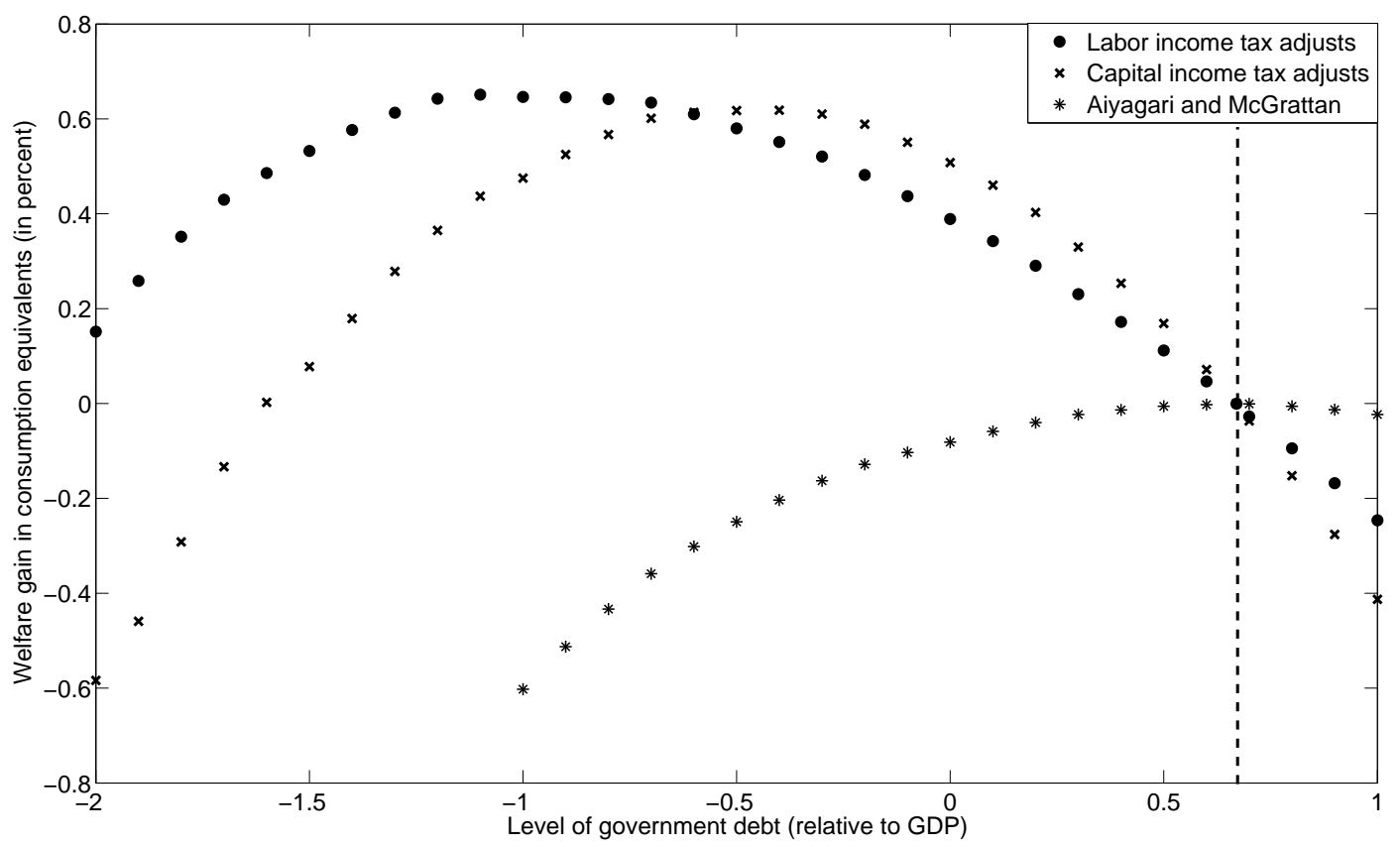

Figure 1: Consumption equivalent change in welfare with respect to benchmark

Figure 1 reveals that it is optimal for the government to hold assets, either of a value of around 50 percent of GDP, if debt is financed by changes in capital income taxation, or of a value of around 110 percent of GDP, if debt is financed by changes in labor income taxation. This result is in contrast to the previous literature, notably Aiyagari and McGrattan (1998), who find that the government should optimally issue debt of around 60 percent of GDP.

The reason for the different outcomes lies in the different calibration of the income process. Recall from table (3) that our calibration implies that the degree of wealth inequality generated by our model is close to the one that is observable in the U.S., where a large fraction of the population holds almost no assets at all. This implies that these households will not benefit from an increase in the interest rate associated with an increase in debt. Consequently, we find that the level effect and the income composition effect of an increase in government debt outweigh the insurance effect.

This finding is line with the recent results in Davila et al. (2007), who compute the constrained 
efficient level of capital in a model with incomplete markets. As we do, they conclude that it is the income composition of the consumption-poor households that matters. If those households depend mainly on labor income which is subject to idiosyncratic productivity shocks, the constrained efficient allocation involves a larger stock of capital than the market economy delivers. The income composition effect is then more decisive for aggregate welfare than the insurance effect.
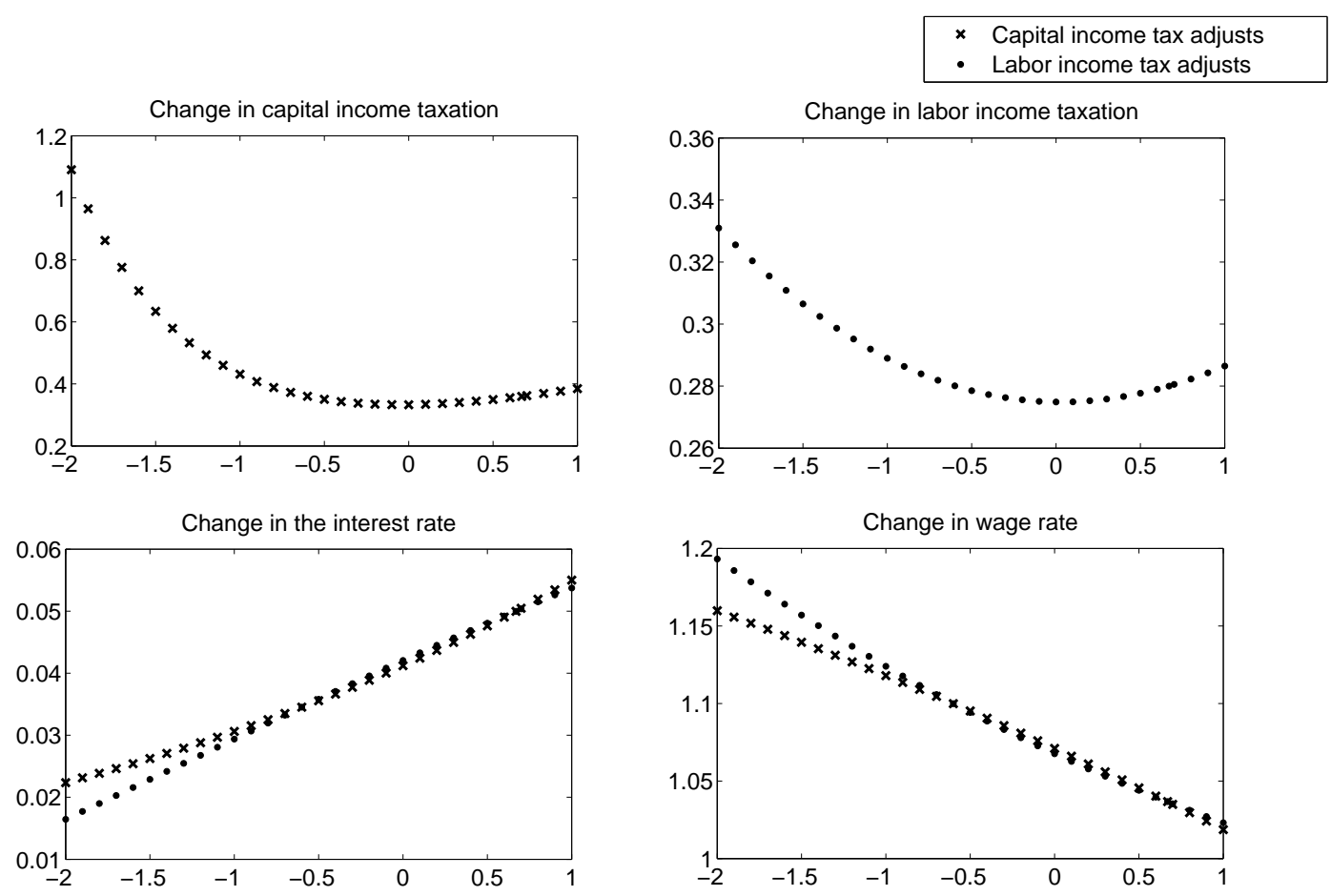

Figure 2: Implied tax rates, interest rates and wage rates for stationary equilibria with different debt levels

Figure 1 also reveals that depending on whether debt is financed by labor taxes or capital taxes, we get a different optimal level of government assets. In order to understand the differences, we first need to understand the general behaviour of tax rates after a change in government debt. First, recall that from the government budget constraint (5), an increase in government debt implies that the government needs to levy more taxes in order to pay the additional interest due, if the government expenditures and transfers are kept fixed. When government debt is reduced however the behaviour of taxes is nonmonotonic, decreasing for modest reductions, but increasing again for higher reductions. The reason is that a lower interest rate, as a consequence of lower government debt reduces the incentive to save. Therefore assets of the households and consequently also the tax base for the capital income tax of the government.

Now, back to the question why the optimal public asset levels are different depending on the form of taxation that is used to equalize the budget. Figure 2 shows that the capital income tax has to change more dramatically to keep the budget balanced after a change of government debt, compared to a situation when the labor income tax adjusts. Consider the role of capital taxation when the government increases its assets (i.e. reduces government debt). As we have argued above the lowering of the interest 
rate leads to an erosion of the tax base. This forces the government to increase the capital tax rate in order to keep its budget balanced, therefore reducing after-tax returns on capital even further. A vicious circle starts.

Now consider the role of labor taxation when the government increases its assets. Again, the interest rate falls and the wage rate rises. The combination of the two causes households to consume more leisure and to work less. However, differently from the case of capital taxation, there is no vicious circle as for capital taxation, but rather a dampening effect: the rising wage dampens the negative incentive effect of an increase of the tax rate. However, increasing the labor income tax rate also dampens the positive effect of higher wages on welfare. Clearly, after-tax wages rise less for a given reduction in government debt than in the case where capital income taxation is used. As a consequence, the optimal level of government debt is about twice as low as in the case where the capital income tax adjusts (-110 percent versus -50 percent of GDP).

Moving towards the optimal level of government assets leads however to relatively small aggregate welfare gains considering the effort it probably means in practice to reduce government debt. Starting from the benchmark reducing government debt relative to GDP by 10 percent (from $\frac{2}{3}$ to 0.6 ) increases welfare to a level equivalent to an average increase in consumption by 0.0715 percent if the capital income tax adjusts and by 0.0474 percent if the labor income tax adjusts. On overall welfare gains up to an equivalent average rise of consumption of 0.618 percent are possible for the case of capital income taxation and of 0.654 percent for the case of labor income taxation. Although the overall effect is already approximately 7.5 times larger than for the specification of Aiyagari and McGrattan (1998), it is still relatively small.

In the next section we show that those small aggregate welfare effects can be decomposed into substantial group-specific welfare effects depending on the wealth group of households that is considered.

\subsection{Welfare of different wealth-groups: poor, middle class, rich}

The policy of changing the level of government debt has different implications depending on which wealth-group is considered. Thus, to fully understand compositional effects on welfare it is useful to consider the evolution of the relative importance of wealth groups and the respective welfare changes for those groups. For this purpose let us define three types of agents according to their wealth:

1. Poor: Agents who are indebted or hold zero assets.

2. Rich: Agents who are part of the group of richest persons who together as a group hold 70 percent of total assets.

3. Middle class: Agents who are neither rich nor poor.

It is important to stress that those groups are exclusive for all specifications considered here. By definition poor households do not have any asset income and therefore care only about their labor income. The poor are thus only affected by changes in wages or labor income taxation. The rich have only little labor income compared to asset income. Therefore they care primarily about changes in the interest rate and capital income taxation. Finally, the middle class is affected by both changes in labor income and changes in capital income. 
Figure 3 shows the change in welfare at different levels of government debt for each wealth-group and the change of the relative size of each wealth-group.
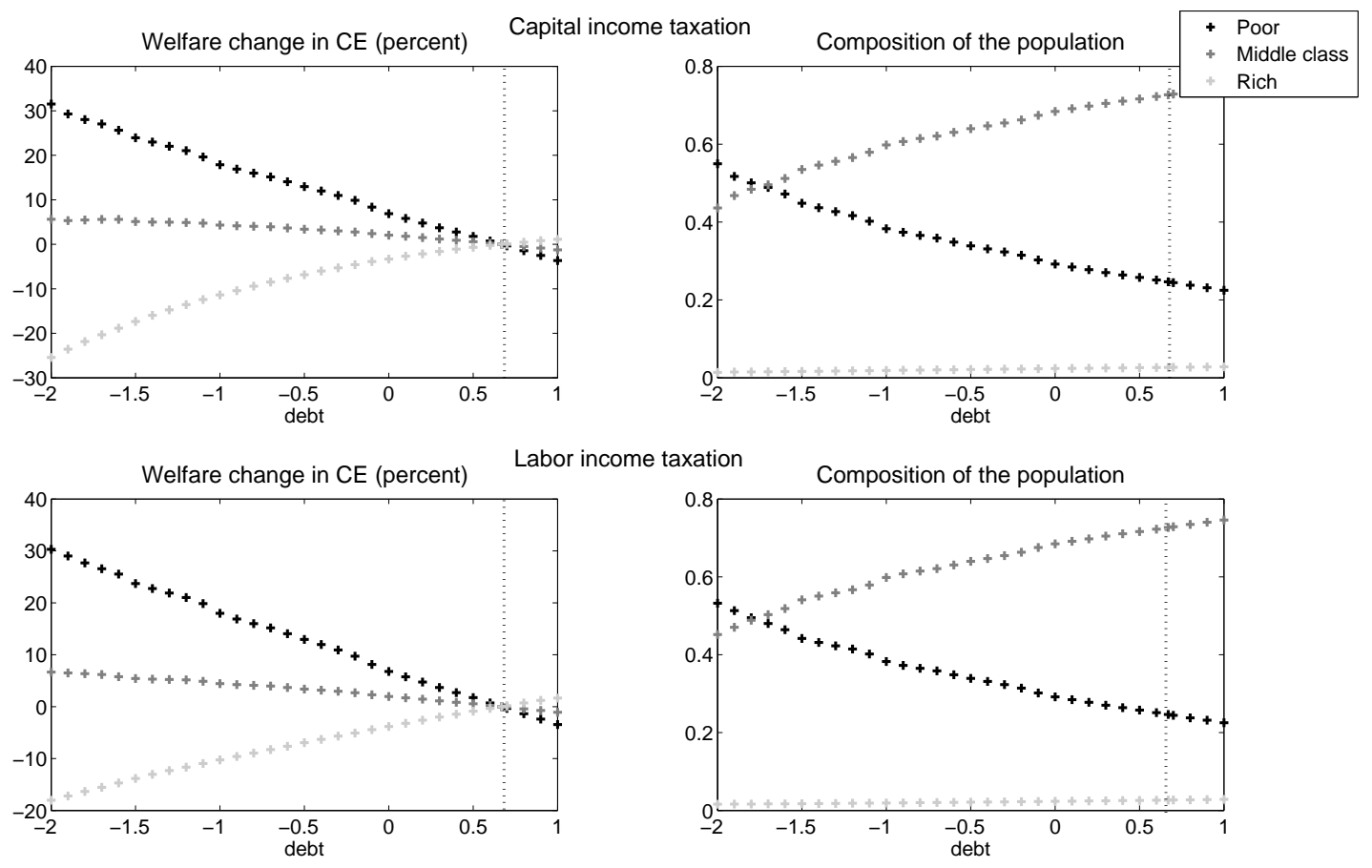

Figure 3: The compositional effects: welfare changes of the poor, the middle class and the rich in comparison

The first thing to note is that there are large group-specific changes in average (group-) welfare (see the left hand side of Figure 3). On aggregate those effects seem to average out, which explains small overall welfare effects. Secondly, a reduction of government debt is good for the poor. The average poor household can gain welfare worth a 0.735 percent ( 0.713 percent) rise in consumption from a 10 percent reduction in government debt, if financed by capital income taxation (labor income taxation). On overall, the average poor household can even gain welfare worth a 12.0 percent (16.9 percent) rise in consumption, if moving to the optimal debt level. Not surprisingly for the poor it would be optimal to reduce debt as much as possible by changing capital income taxation.

Thirdly, the welfare changes seem to be concave for the rich in the case of capital taxation. In other words the average rich household has much to lose if government debt is reduced, but not a lot to gain, if it is increased. The reason is that the change in taxes is non-monotonic, as mentioned in the last section. When government debt rises the rich gain from the rise in interest, but lose from higher taxes. When government debt is reduced from a certain level onwards they lose from both higher taxes and lower interest rates.

Finally, there is an effect of government debt on the relative size of wealth groups. A reduction of government debt increases the number of wealth-poor in the population relative to the middle class (see the right hand side of Figure 3). Intuitively saving is discouraged because of lower interest rates. This increase in the number of poor leads to a falling tax base and eventually higher taxes. Thus an 
'optimum' level arises from which onwards high tax distortions become overwhelming. ${ }^{10}$

In the next section we analyze how the results change when we also include the transitional periods into the welfare analysis.

\subsection{Welfare over the transition path}

In the previous section, we computed the optimal long-run level of government debt by comparing stationary equilibria. Our results suggested that the government should optimally hold assets.

One might wonder whether this conclusion still holds when we take the transition between two stationary equilibria into account. Clearly, if government debt is reduced and if the government keeps its expenditures fixed, it follows from the budget constraint that taxes have to be increased during the period during which debt is reduced.

In this section we argue that it is possible to gain from a reduction in government debt although either consumption or leisure (or both) need to be sacrificed in the short run. We assume that in period $t$, the government (unexpectedly) increases the capital income tax for one period to $100 \%$. This upper bound is chosen such that capital owners are not expropriated. The revenues of this tax increase are then used to reduce government debt. This in turn allows the government to reduce either capital income taxes (scenario 1) or labor income taxes (scenario 2) from period $t=2$ onwards. The experiment is inspired by ?), who show that in order to achieve a Pareto-optimal tax reform the government should leave capital taxes high in the short run and reduce then to zero in the long run.

We find that it is possible to reduce government debt to $56.54 \%$ in scenario 1 and to $56.47 \%$ in scenario 2 (see Table 4). Under both scenarios, total welfare gains from reducing government debt are positive, namely $+0.007 \%$ in scenario 1 or $+0.026 \%$ in scenario 2 . This holds despite the fact that substantial welfare costs occur during the transition, a finding that we explain in more detail in the following. Notice that it seems more promising to reduce long run labor income taxes. In order to better understand the

Table 4: Welfare changes over the transition path

\begin{tabular}{crrr}
\hline \hline Tax reduced in long run & $\begin{array}{c}\text { New debt to } \\
\text { GDP level }\end{array}$ & \multicolumn{2}{c}{ Welfare change relative to benchmark } \\
excl. transition path & incl. whole transition path \\
\hline Scenario 1: Capital income tax & $56.54 \%$ & $+0.106 \%$ & $+0.007 \%$ \\
\hline Scenario 2: Labor income tax & $56.47 \%$ & $+0.107 \%$ & $+0.026 \%$ \\
\hline \hline
\end{tabular}

intuition behind our results, we plotted the path of the capital stock, of labor supply, of the after-tax interest rate and of the after-tax wage rate in Figure 4. ${ }^{11}$ Recall from the long-run analysis above that when government debt is reduced, this crowds in private capital. This stems from the fact that borrowing constraints are binding for some households. These households do not dissave, despite the fact that taxes are expected to be lower in the future. As a result, the private capital stock rises and the equilibrium interest rate falls (see first picture of Figure 4).

\footnotetext{
${ }^{10}$ Reducing government debt thus reduces inequality in the long run, a result that was already emphasized by Flodén (2001).

${ }^{11}$ Note that the figure omits the first period for the after-tax interest rate, because in this period capital taxes are $100 \%$ by definition of our experiment. This means that the after-tax interest rate is 0 in the first period. This hinders the readability of the figure, so we left it out.
} 

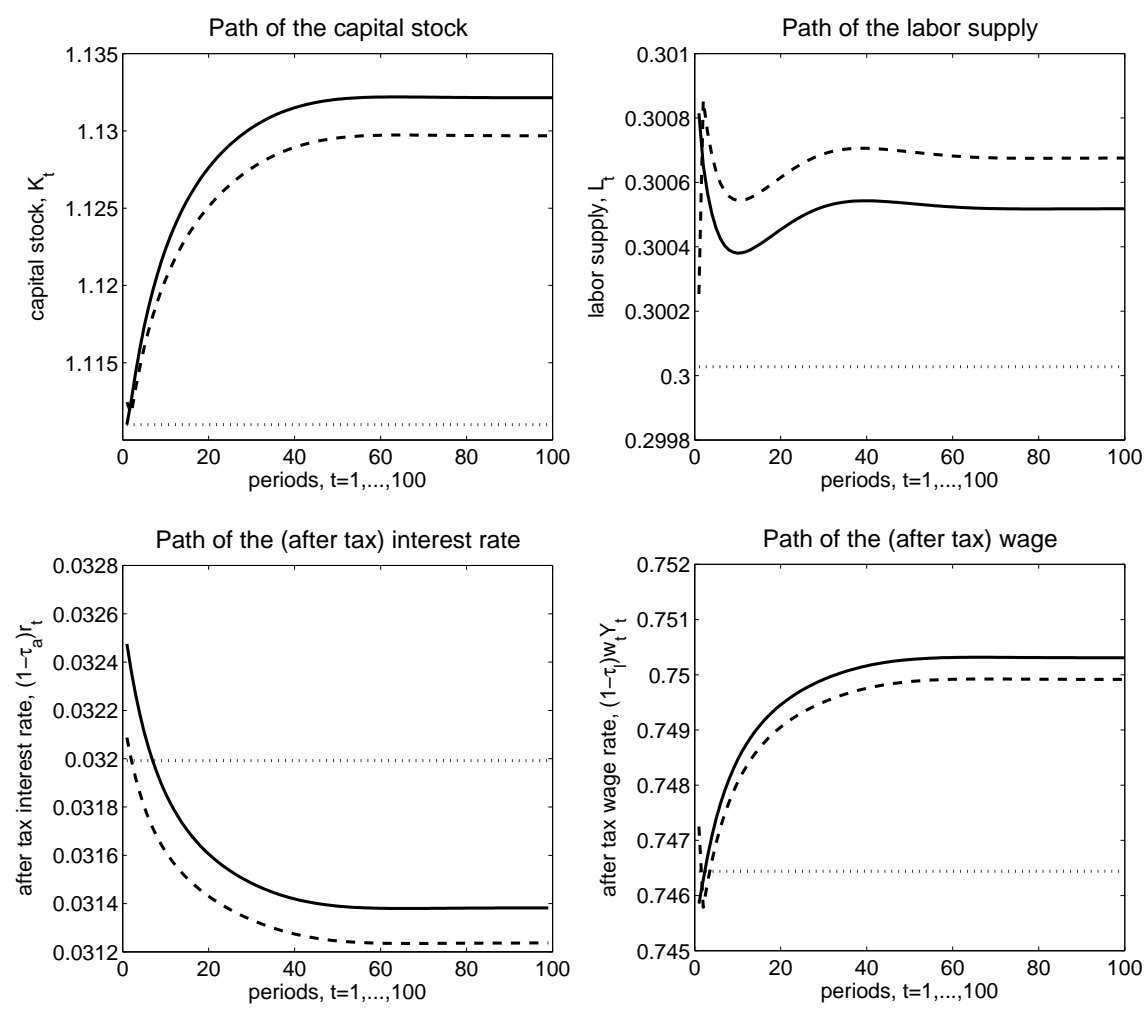

- Scenario 1: Capital income tax adjusts - - - Scenario 2: Labor income tax adjusts Benchmark SS

Figure 4: Implied capital stock, labor supply, interest rates and wage rates for the transition experiment

However in the short run there is an additional effect from the one-period tax increase, stemming from the fact that the capital income of one period is taxed away. This is a negative income effect, and because leisure is a normal good, households consume less leisure and increase their labor supply (see second picture of Figure 4). This in turn leads to a short run increase in the interest rate and decrease in the wage rate (see third and fourth picture of Figure 4). This hurts in particular borrowing constrained households, because they depend solely on their wage income. Moreover they already work the maximum hours, so they cannot respond to lower wages by working more. Because the borrowing constrained household are the consumption-poor, there are high welfare costs are associated along the transition path. Interestingly, in scenario 2 this adverse effect is dampened, because of an intertemporal substitution effect resulting from the fact that labor taxes will be lowered from period 2 onwards. Households are willing to increase leisure today in exchange for less leisure tomorrow. This explains why wages are below the benchmark level for a shorter time than for scenario 1 . Welfare losses are lower.

The best policy given the possibilities analyzed here is thus to reduce government debt by setting a high capital income tax today and use the lighter budget to lower labor income taxes from period 2 onwards.

However, a caveat to this analysis is that we do not explicitly aim at calculating the optimal path of capital and labor income taxes over the transition. It is possible that there is a different timing of 
taxes which produces even higher welfare gains. ${ }^{12}$

The next section shows the welfare effects of this policy for different wealth groups over the transition path.

\subsection{Welfare effect on different wealth groups over the transition path}

In this section we show that households with little wealth have the highest welfare loss during the transition, while relatively affluent households gain relative to the benchmark stationary equilibrium

(see Table 5). Interestingly, the group that benefits the most from reducing government debt in the long-run suffers the most in the short-run (and vice versa).

The intuition behind this striking result is as follows. Recall from Figure 4 that output and thus also wages are higher in the long-run, compared to periods after the lower debt level was implemented. This is due to the fact that reducing government debt crowds in private capital. Since households are rational, they foresee this. As a result, households would like to reduce their savings today, or borrow more, respectively. Those who are borrowing constrained cannot do so, however. Thats why it is the wealth-poor who loose during the transition.

Why is the wage lower in the first few periods? The reason is that the funds for paying back government debt are taken from households that own wealth and partly depend on their asset income. They have to forego asset income for one period. There are two ways of dealing with such a situation, where there is less asset income: dissave or work more. In fact wealthy households will do both. Thus the general level of labor supply rises as can be seen in Figure 4. As discussed above this is harmful for borrowing constrained agents who depend solely on labor income and virtually already work as much as possible.

Notice that the loss is more pronounced for households that are hit by a particularly good or a particularly bad income shock (wealth-poor only) in the period when the reduction of the government debt takes place. This is show in Table 6 where we decompose welfare changes in the first period of the transition with respect to wealth groups and income states. Clearly, the effect of borrowing constraints is exacerbated for the wealth-poor if they are hit by a bad income shock, which explains why they loss is more pronounced for this group. However, households with the best earnings draws loose by even more, irrespectively of their wealth holdings. The reason is as follows: households with the highest earnings shocks expect a lower earnings in the future. This is true even though average earnings are increasing over the transition path. ${ }^{13}$ Households in this group therefore do not want to dissave, but rather

\footnotetext{
${ }^{12}$ We have shown that the welfare effects of government debt change dramatically with a careful modelling of wealth inequality. The downside of this greater precision of the wealth distribution is however that the computation of the stationary wealth distribution is more time consuming (see for example Heer and Maussner (2009) as a reference on different methods for computing the stationary wealth distribution and their performance in terms of precision and computing time). Therefore finding the 'optimal' path of transition which involves iterating over the whole path of interest rates, wage rates and tax rates is a difficult task. (Note that with endogenous labor there is an additional adjustment). Greulich and Marcet (2008) go in this direction by analyzing optimal capital, labor income taxes and resulting government debt holdings in a model with heterogenous agents. However they miss important aspects because they do not include individual risk and borrowing constraints. Extending their results to an Aiyagari-framework as presented here would thus be very valuable but exceeds the aim of this paper. Therefore we leave it to future research for now.

${ }^{13}$ Recall that our calibration implies substantial difference between the highest and the other realization of the income
} 
Table 5: Welfare effect on different wealth groups

\begin{tabular}{crr}
\hline \hline Quintiles & \multicolumn{2}{c}{ Welfare change relative to benchmark } \\
& excl. transition path & incl. whole transition path \\
\hline Capital income tax & & \\
\hline Q1 $(20 \%$ poorest $)$ & $+0.496 \%$ & $-31.067 \%$ \\
Q2 $(20 \%-40 \%)$ & $+0.300 \%$ & $-3.656 \%$ \\
Q3 $(40 \%-60 \%)$ & $+0.182 \%$ & $+6.825 \%$ \\
Q4 $(60 \%-80 \%)$ & $+0.112 \%$ & $+13.118 \%$ \\
Q5 (20\% richest) & $-0.798 \%$ & $+49.566 \%$ \\
\hline Labor income tax & & $-31.115 \%$ \\
\hline Q1 $(20 \%$ poorest $)$ & $+0.505 \%$ & $-3.691 \%$ \\
Q2 $(20 \%-40 \%)$ & $+0.310 \%$ & $+6.939 \%$ \\
Q3 (40\%-60\%) & $+0.188 \%$ & $+13.232 \%$ \\
Q4 (60\% - 80\%) & $+0.114 \%$ & $+49.497 \%$ \\
Q5 (20\% richest) & $-0.797 \%$ & \\
\hline \hline
\end{tabular}

${ }^{*}$ Welfare gains in consumption units in percent.

Table 6: Welfare effect in the first transition period for wealthincome-groups

\begin{tabular}{|c|c|c|c|c|}
\hline \multicolumn{5}{|c|}{ Capital income tax } \\
\hline & State 1 & State 2 & State 3 & State 4 \\
\hline Poor & $-58.143 \%$ & $-46.496 \%$ & $-40.456 \%$ & $-75.035 \%$ \\
\hline Middle Class & $-18.012 \%$ & $-19.052 \%$ & $-28.656 \%$ & $-73.562 \%$ \\
\hline Rich & $+12.057 \%$ & $+17.777 \%$ & $+6.946 \%$ & $-55.212 \%$ \\
\hline \multicolumn{5}{|c|}{ Labor income tax } \\
\hline & State 1 & State 2 & State 3 & State 4 \\
\hline Poor & $-58.122 \%$ & $-46.435 \%$ & $-40.237 \%$ & $-74.948 \%$ \\
\hline Middle Class & $-18.028 \%$ & $-28.351 \%$ & $-28.351 \%$ & $-73.470 \%$ \\
\hline Rich & $+12.135 \%$ & $+17.930 \%$ & $+7.225 \%$ & $-55.100 \%$ \\
\hline
\end{tabular}

${ }^{*}$ Welfare gains in consumption units in percent.

engage in precautionary saving against the event of receiving lower earnings draws in the future. This can be done both through adjusting labor supply and working longer hours and through accumulating additional savings. Because the wage rate is lower initially and households foresee a falling interest rate, they need to save more now relative to the benchmark to provide for possibly lower labor productivity in the future.

The fact that borrowing constraints play a crucial role in explaining the welfare cost of the transition suggests that the policy that directly targets transfers to the wealth-poor could reduce the welfare losses significantly, making it even more profitable to reduce government debt. We leave this for future shock. 
research and conclude this section by stressing that in order to fully assess the welfare costs of fiscal policy in the short and in the long-run, understanding the interaction between borrowing constraints and wealth inequality are key.

In the next section, we thus go one step further and relax the assumption that borrowing constraints are exogenous. As we will see, this gives us even higher welfare gains in the long-run.

\subsection{Endogenous borrowing limit}

In section 4 we have shown how our model can be extended to include endogenous borrowing limits by assuming limited commitment of households to repay loans. This is important because borrowing limits then have to change endogenously as a response to a change in government debt.

In this section we will thus analyze the version of our model with endogenous borrowing limits to see how this endogeneity potentially changes the results about the optimal long run level of government debt. We focus again on stationary equilibria to gain an intuition about the long run effects and be comparable to the previous literature which mainly focussed on stationary equilibria as well.

Figure 5 shows that, in fact, there is an endogenous reaction of borrowing limits to differences in government debt. Borrowing limits are tighter in stationary equilibria where government debt is higher
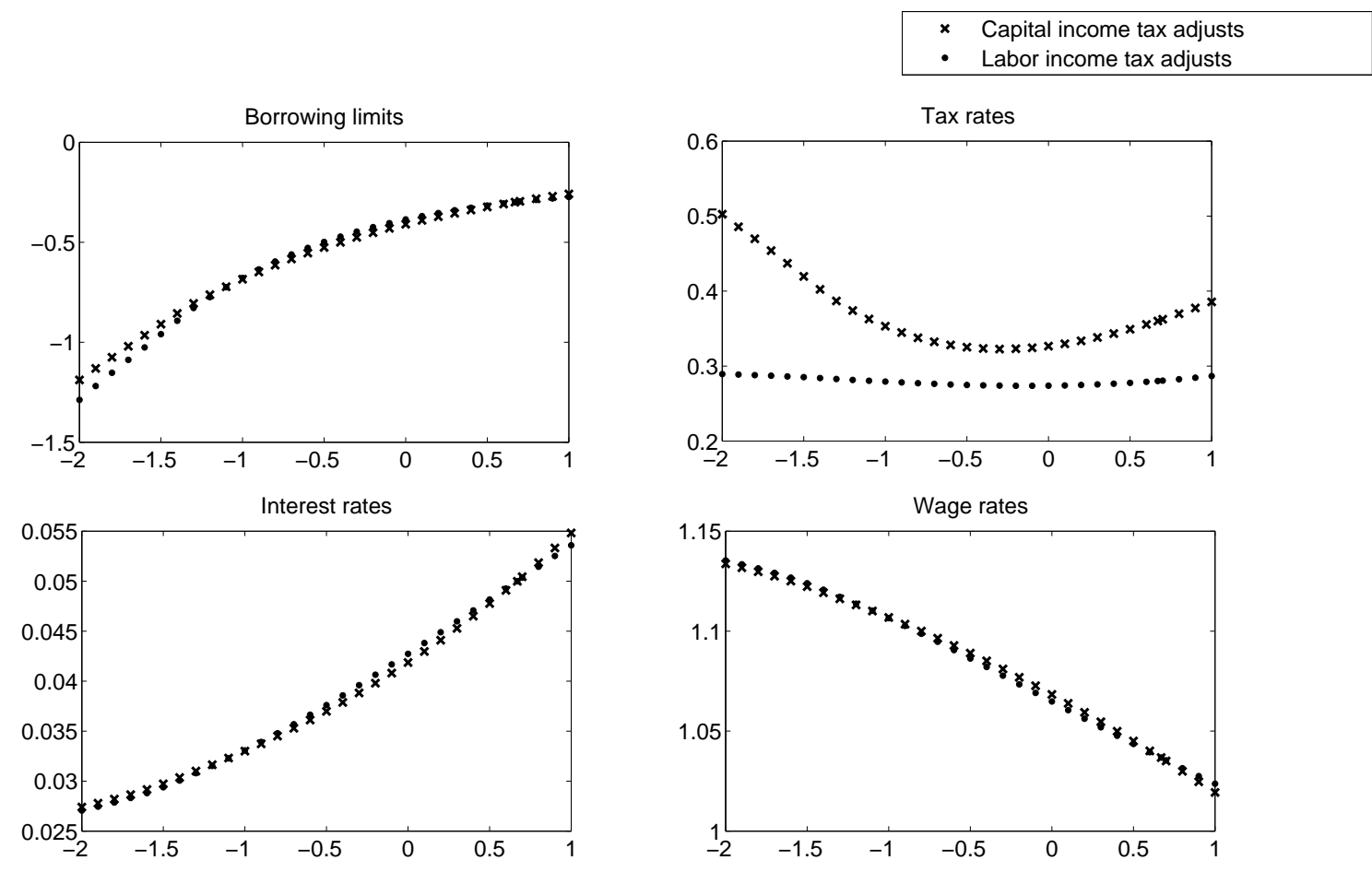

Figure 5: Implied tax rates, interest rates and wage rates for stationary equilibria with different debt levels in the case of endogenous borrowing limits

and looser in stationary equilibria with lower government debt. More precisely, an increase (decrease) of government debt and the subsequent rise (fall) of interest rates due to crowding out (crowding in) leads 
to the borrowing limit of the lowest income group being tighter (looser). ${ }^{14}$ What is the intuition behind this tightening (loosening)? When there is more government debt a higher interest rate and a lower wage rate arise in the new equilibrium. How the borrowing limits react depends on the relative attractiveness of autarky. A higher interest rate makes autarky more attractive relatively to being at the borrowing limit, because a household that is at the borrowing limit has to pay a higher debt service. The effect of the wage rate depends on how much households adjust their labor supply to smooth consumption and leisure. Households tend to use more extensively adjustments through labor supply when being in autarky than when they are part of financial markets. The reason is that in the latter case they have an additional means of smoothing consumption and leisure through savings and dissavings. A lower wage rate thus makes financial autarky less attractive, because here the household has to rely solely on adjustments to labor supply to smooth consumption and leisure. For low income households this wage effect is not important as they have to work hard regardless of being in autarky or being part of financial markets. Thus the interest rate effect dominates the wage rate effect for the lowest income group. Therefore with higher government debt and a higher interest rate the borrowing limit of this income group will become tighter and vice versa for a lower government debt.

The endogenous reaction of borrowing limits leads to a dampening effect on aggregate variables such as the interest rate, the wage rate and the tax rate (see Figure 5). The distribution of wealth however changes faster than with exogenous borrowing limits (see Figure 6). To gain an intuition, consider for example a reduction in government debt. If borrowing limits become looser instead of staying fixed, agents that in the case of fixed borrowing limits would like but are not able to, now can borrow more. The wealth distribution thus changes more dramatically. However this means also less a dampening effect on the changes of aggregate variables such as the interest rate and the wage rate. The reason is that the demand for savings is reduced and absorbs some of the reduction in asset supply that occurs because government debt is reduced.

Remarkably the endogeneity of borrowing limits leads to quite different welfare effects (see Figure 7). Firstly, the optimal level of welfare is farther to the left in both the case of labor and the case of capital income taxation. It is now optimal for the government to hold assets of around $160-170$ percent of GDP. Intuitively, the reaction of the borrowing limits procures a higher welfare to poor agents without having to incur high tax distortions. The reason is that the reaction of the tax rate is "slower" due to the dampening effect of endogenous borrowing limits as discussed above.

Second there are sort of "double peaks" in the shape of the aggregate welfare change. To understand the reason for this difference to the case of exogenous borrowing limits, it is useful to look once more at the compositional effects. Figure 6 shows how the welfare of different wealth-groups in the population changes. At first when there are still a minority of poor in the population the positive welfare effect of a higher wage on that group is not so strong given that the wage also changes slower. Thus at first welfare increases less steeply than in the case of exogenous borrowing limits (see Figure 7). But subsequently as the number of poor increases faster for higher levels of government assets welfare begins to increase more steeply. Similarly to the case of exogenous borrowing limits at very high asset levels the negative effect of having a higher number of poor with generally lower welfare begins to matter more than that their welfare rises a little bit. Consequently as seen in Figure 7 welfare starts to fall again. This mechanism

\footnotetext{
${ }^{14}$ Remember that due to our specification of the transition matrix of income shocks the borrowing limit of the lowest income group is the relevant one for any household.
} 

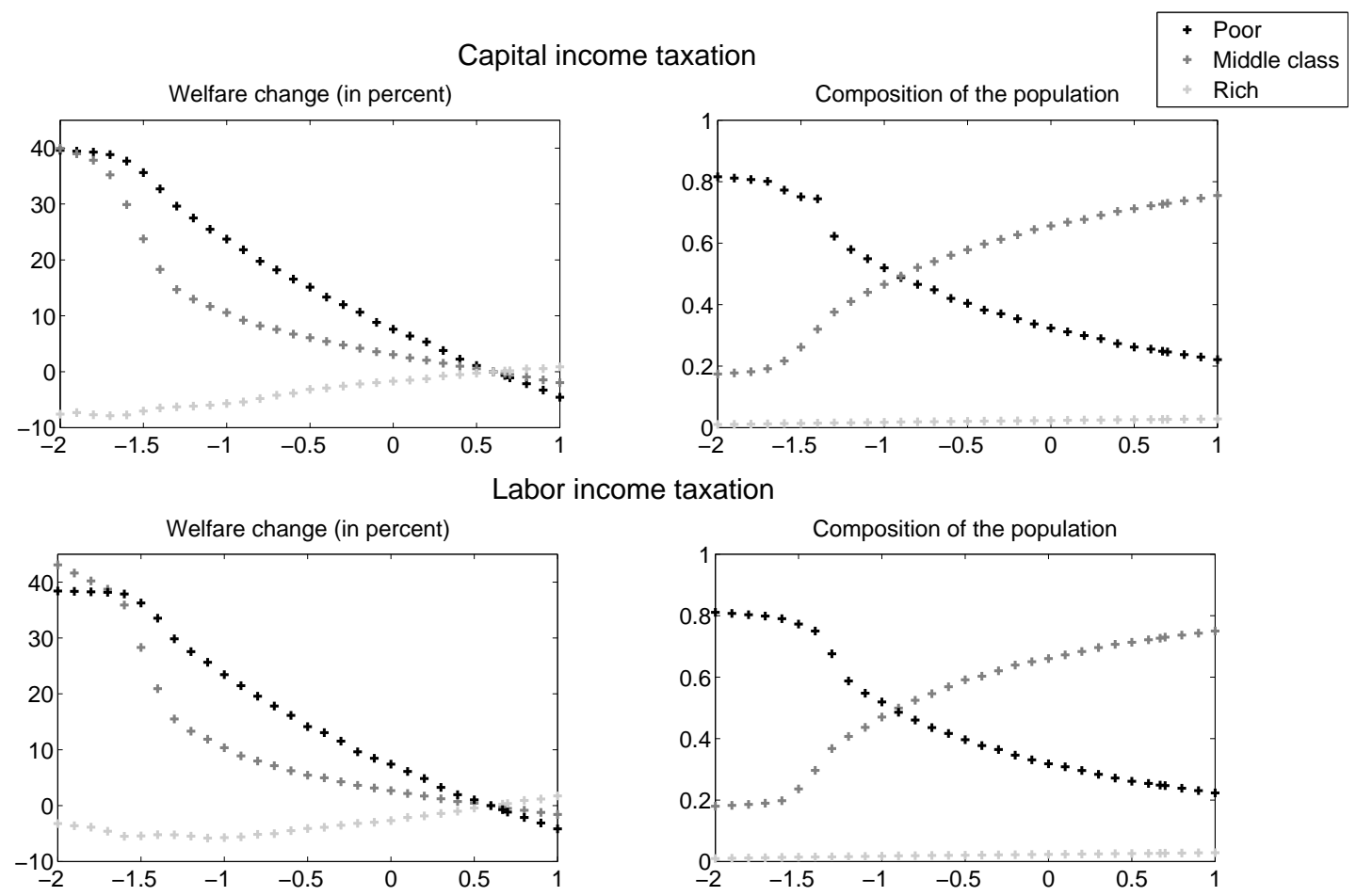

Figure 6: The compositional effects: welfare changes of the poor, the middle class and the rich in comparison in the case of endogenous borrowing limits

translates into a different shape of the welfare change.

\section{Conclusion and further research}

As shown by Davila et al. (2007) the competitive equilibrium in an incomplete markets model is 'constrained inefficient' and there is scope for public policy. In this paper we show that government debt can be used to implement an allocation nearer to the constrained efficient one. However, different than previously argued we show that if calibrating the model to the actual wealth distribution, the government should, in the long run, rather accumulate assets suggesting that the capital stock is too low under laissez-faire.

Asset-poor agents profit most from the reduction of government debt in the long run. The reason is that the increase in the wage affects them strongly as their income consists primarily of wage income. However lower interest rates mean that the incentives to save are decreased so that the number of asset-poor agents in the population increases. This leads to a falling tax base and higher taxes. An 'optimum' exists from which onwards high tax distortions become overwhelming.

To reach this new stationary equilibrium we propose a policy of setting the capital income tax to the maximum for one period, reduce government debt and using the lighter budget to reduce labor taxes afterwards. This analysis shows that at least some welfare gains can be achieved by reducing government debt. However the results about relative welfare changes are reversed relative to the long run. Assetpoor agents lose consumption and/or leisure over the transition because of temporarily lower wages and 


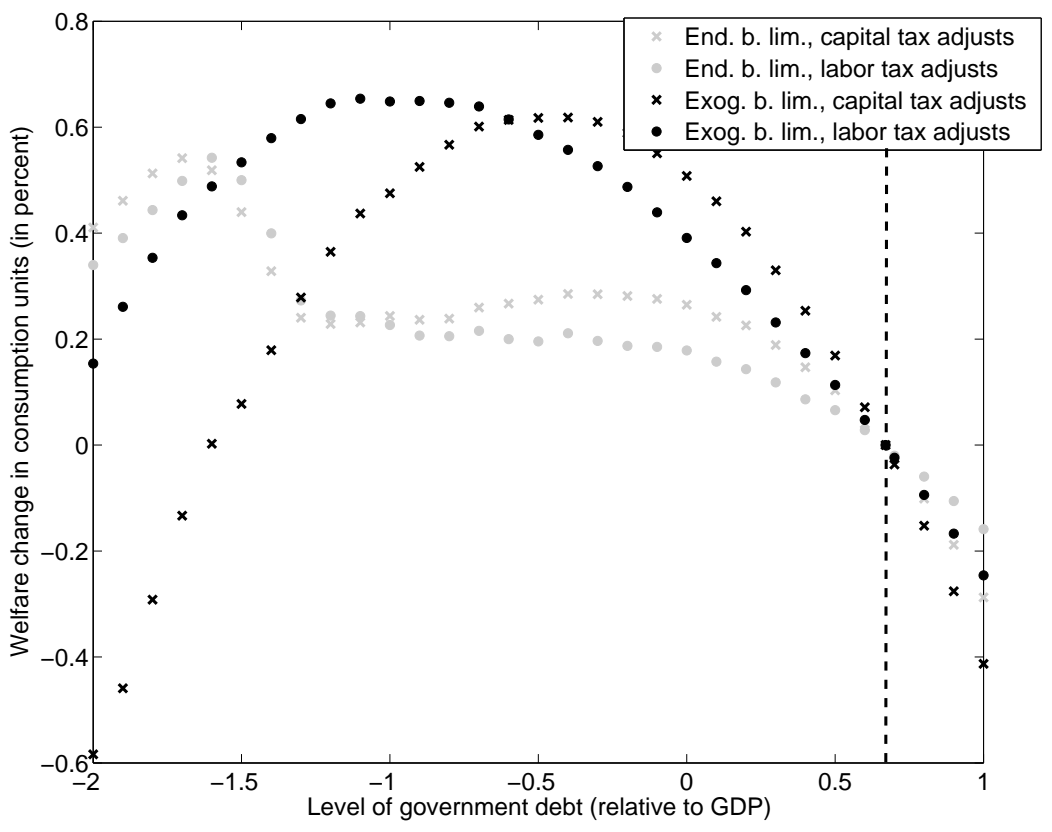

Figure 7: Consumption equivalent change in welfare with respect to benchmark in the case of endogenous borrowing limts

less insurance opportunities. Further research has to show if those negative transitional effects on the weakest chains of society could be alleviated by using targeted transfers.

Endogenizing borrowing limits leads to even higher optimal levels of government assets in the long run as part of the effect on the equilibrium in the asset market (and thus on the equilibrium interest rate) is absorbed by the reaction of the borrowing limits. On the one hand this makes the insurance effect weaker, on the other hand there is an additional insurance effect from the reaction of borrowing limits which permits households to borrow more. In this sense public and private insurance concur with each other. As a result government debt is even less appropriate as an insurance channel. Further research in this direction could include the analysis of transitional welfare effects or the use of transfers as insurance. Summarizing we have shown that in an incomplete markets model which maps the high wealth inequality in the U.S. the government can achieve welfare gains by reducing government debt especially in the long run. The only source of uncertainty in our model are idiosyncratic income shocks. A possible extension would be to additionally include aggregate shocks to include a motive for tax smoothing like in Barro (1979), Lucas and Stokey (1983), Aiyagari et al. (2002) or Heathcote (2005). Another possible extension concerns the transition to the new stationary equilibrium. With respect to transitional effects it would be interesting to analyze the optimal tax mix as well as the timing of taxes for our calibration (extending results of Greulich and Marcet, 2008 and Heathcote, 2005). 


\section{References}

Ábrahám, Árpád, and Eva Cárceles-Poveda. 2008. "Tax Reform with Endogenous Borrowing Limits and Incomplete Asset Markets." Unpublished.

—. 2010. "Endogenous Trading Constraints with Incomplete Asset Markets." Journal of Economic Theory 145 (3): 974-1004 (May).

Aiyagari, S. Rao, Albert Marcet, Thomas J. Sargent, and Juha Seppala. 2002. "Optimal Taxation without State-Contingent Debt." Journal of Political Economy 110 (6): 1220-1254 (December).

Aiyagari, S. Rao, and Ellen R. McGrattan. 1998. "The Optimum Quantity of Debt." Journal of Monetary Economics 42 (3): 447-469 (October).

Aiyagari, S Rao. 1994. "Uninsured Idiosyncratic Risk and Aggregate Saving." The Quarterly Journal of Economics 109 (3): 659-84 (August).

- 1995. "Optimal Capital Income Taxation with Incomplete Markets, Borrowing Constraints, and Constant Discounting." Journal of Political Economy 103 (6): 1158-75 (December).

Albanesi, Stefania. 2008. "Comment on: \&quot;Markets versus Governments\&quot; by Acemoglu, Golosov and Tsyvinski." Journal of Monetary Economics 55 (1): 190-195 (January).

Alvarez, Fernando, and Urban J. Jermann. 2000. "Efficiency, Equilibrium, and Asset Pricing with Risk of Default." Econometrica 68 (4): 775-798 (July).

Attanasio, Orazio, and José-Víctor Ríos-Rull. 2000. "Consumption Smoothing in Island Economies: Can Public Insurance Reduce Welfare?" European Economic Review 44 (7): 1225-1258 (June).

Barro, Robert J. 1979. "On the Determination of the Public Debt." Journal of Political Economy 87 (5): 940-71 (October).

Castañeda, Ana, Javier Díaz-Giménez, and José-Víctor Ríos-Rull. 2003. "Accounting for the U.S. Earnings and Wealth Inequality." Journal of Political Economy 111 (4): 818-857 (August).

Chatterjee, Satyajit, Dean Corbae, Makoto Nakajima, and Jos-Vctor Ros-Rull. 2007. "A Quantitative Theory Of Unsecured Consumer Credit With Risk Of Default." Econometrica 75:1525-1689.

Cooley, Thomas F., and Edward C. Prescott. 1995. "Economic Growth and Business Cycles." In Frontiers of Buesiness Cycle Research, edited by Thomas F. Cooley. Princeton University Press.

Davila, Julio, Jay H. Hong, Per Krusell, and José-Víctor Ríos-Rull. 2007. "Constrained Efficiency in the Neoclassical Growth Model with Uninsurable Idiosyncratic Shocks." Unpublished.

Díaz-Gímenez, J., V. Quadrini, and José-Víctor Ríos-Rull. 1997. "Dimensions of Inequality: Facts on the U.S. Distributions of Earnings, Income and Wealth." Federal Reserve Bank of Minneapolis Quarterly Review 21:3-21.

Flodén, Martin. 2001. "The Effectiveness of Government Debt and Transfers as Insurance." Journal of Monetary Economics 48 (1): 81-108 (August).

Gomes, Francisco, Alexander Michaelides, and Valery Polkovnichenko. 2008. "Fiscal Policy in an Incomplete Markets Economy." Unpublished. 
2. 2010. "Quantifying the Distortionary Fiscal Cost of 'The Bailout'." Cepr discussion paper DP7941, Centre for Economic Policy Research.

Gottardi, Piero, Atsushi Kajii, and Tomoyuki Nakajima. 2010, 01. "Constrained Inefficiency and Optimal Taxation with Uninsurable Risks." Economics working papers ECO2010/02, European University Institute.

Greulich, Katharina, and Albert Marcet. 2008, February. "Pareto-Improving Optimal Capital and Labor Taxes." Ufae and iae working papers 733.08, Unitat de Fonaments de l'Anàlisi Econòmica (UAB) and Institut d'Anàlisi Econòmica (CSIC).

Heathcote, Jonathan. 2005. "Fiscal Policy with Heterogeneous Agents and Incomplete Markets." Review of Economic Studies 72 (1): 161-188 (01).

Heer, Burkhard, and Alfred Maussner. 2009. Dynamic General Equilibrium Modeling. 2. Springer.

Kehoe, Timothy J, and David K Levine. 2001. "Liquidity Constrained Markets versus Debt Constrained Markets." Econometrica 69 (3): 575-98 (May).

Krueger, Dirk, and Fabrizio Perri. 2006. "Does Income Inequality Lead to Consumption Inequality? Evidence and Theory." Review of Economic Studies 73 (1): 163-193 (01).

— 2010. "Public versus Private Risk Sharing." Forthcoming in: Journal of Economic Theory.

Livshits, Igor, James MacGee, and Michle Tertilt. 2007, September. "Accounting for the Rise in Consumer Bankruptcies." Nber working papers 13363, National Bureau of Economic Research, Inc.

Lucas, Robert, and Nancy Stokey. 1983. "Optimal Fiscal and Monetary Policy in an Economy without Capital." Journal of Monetary Economics 12 (1): 53-93.

Mendoza, Enrique G., Assaf Razin, and Linda L. Tesar. 1994. "Effective Tax Rates in Macroeconomics: Cross-Country Estimates of Tax Rates on Factor Incomes and Consumption." Journal of Monetary Economics 34 (3): 297-323 (December).

Oh, Hyunseung, and Ricardo Reis. 2010. "Targeted Transfers and The Great Recession." Mimeo.

Trabandt, Mathias, and Harald Uhlig. 2009, September. "How Far Are We From The Slippery Slope? The Laffer Curve Revisited." Nber working papers 15343, National Bureau of Economic Research, Inc.

Woodford, Michael. 1990. "Public Debt as Private Liquidity." American Economic Review 80 (2): 382-88 (May).

Zhang, Harold H. 1997. "Endogenous Borrowing Constraints with Incomplete Markets." Journal of Finance 52 (5): 2187-2209 (December). 


\section{Appendix}

\section{Detrended formulation of the household maximization problem}

In our model, there is a balanced growth path along which variables will be growing at the rate of technology growth. To find the stationary equilibrium of the model or to compute the transition from one stationary equilibrium to another it is useful to first detrend variables with respect to this exogenous productivity growth component to obtain a formulation where variables are constant in the balanced growth equilibrium. (This procedure was also used in the earlier literature, for example by Aiyagari and McGrattan, 1998 and Flodén, 2001). Denote a detrended variable by "tilde": $\tilde{x}=\frac{x}{Y}$. The present value of lifetime utility (for a Cobb-Douglas can then be denoted as follows:

$$
U\left(\left\{\tilde{c}_{t}\right\}_{t=1,2, \ldots},\left\{l_{t}\right\}_{t=1,2 \ldots}\right)=E_{0} \sum_{t=0}^{\infty} \beta^{t} Y_{t}^{\eta(1-\mu)} u\left(\tilde{c}_{t}, l_{t}\right)
$$

Now using the fact that $Y_{t}=Y_{0}(1+g)^{t}$, where $Y_{0}$ is output in period 0 , we can write:

$$
\begin{aligned}
U\left(\left\{\tilde{c}_{t}\right\}_{t=1,2, \ldots},\left\{l_{t}\right\}_{t=1,2 \ldots}\right) & =Y_{0}^{\eta(1-\mu)} E_{0} \sum_{t=0}^{\infty} \beta^{t}(1+g)^{t \eta(1-\mu)} u\left(\tilde{c}_{t}, l_{t}\right) \\
& =Y_{0}^{\eta(1-\mu)} E_{0} \sum_{t=0}^{\infty} \tilde{\beta}^{t} u\left(\tilde{c}_{t}, l_{t}\right)
\end{aligned}
$$

where $\tilde{\beta}=\beta \cdot(1+g)^{\eta(1-\mu)}$.

Similarly, we can find a detrended version of the household budget constraint by dividing it by $Y_{t}$ :

$$
\begin{aligned}
\frac{c_{t}}{Y_{t}}+\frac{Y_{t+1}}{Y_{t}} \frac{a_{t+1}}{Y_{t+1}} & =\frac{\bar{w}_{t}}{Y_{t}} \epsilon_{t}\left(1-l_{t}\right)+\left(1+\bar{r}_{t}\right) \frac{a_{t}}{Y_{t}}+\chi \\
\tilde{c}_{t}+(1+g) \tilde{a}_{t+1} & =\tilde{\bar{w}}_{t} \epsilon\left(1-l_{t}\right)+\left(1+\bar{r}_{t}\right) \tilde{a}_{t}+\tilde{\chi}_{t}
\end{aligned}
$$

Also the borrowing constraint can be detrended:

$$
\tilde{a}_{t+1} \geq \underline{\tilde{a}}_{t}
$$

The resulting recursive formulation in detrended variables is given by:

$$
\begin{aligned}
W(\tilde{a}, \epsilon ; \theta) & =\max _{\tilde{a}^{\prime}, \tilde{c}, l} Y_{0}^{\eta(1-\mu)} u(\tilde{c}, l)+\tilde{\beta} \sum_{\epsilon^{\prime}} \pi\left(\epsilon^{\prime} \mid \epsilon\right) W\left(\tilde{a}^{\prime}, \epsilon^{\prime} ; \theta^{\prime}\right) \\
\text { s.t. } \tilde{c}+(1+g) \tilde{a}^{\prime} & =\tilde{w} \epsilon(1-l)+(1+\bar{r}) \tilde{a}+\tilde{\chi} \\
\tilde{a}^{\prime} & \geq \underline{\tilde{a}} \\
\theta^{\prime} & =\Gamma[\theta]
\end{aligned}
$$




\section{Ricardian equivalence under a natural borrowing limit but not under a bind- ing "ad hoc" borrowing limit}

The optimal sequences for consumption, leisure and savings have to satisfy the following first order conditions in every period $t$ for every possible state $\epsilon_{t}$ :

$$
\begin{aligned}
\frac{u_{l}\left(c_{t}^{*}, l_{t}^{*}\right)}{u_{c}\left(c_{t}^{*}, l_{t}^{*}\right)} & =\epsilon \bar{w}_{t} \\
\frac{\beta \sum_{\epsilon_{t+1}} \pi\left(\epsilon_{t+1} \mid \epsilon_{t}\right) u_{c}\left(c_{t+1}^{*}, l_{t+1}^{*}\right)}{u_{c}\left(c_{t}^{*}, l_{t}^{*}\right)} & =\frac{1}{1+\bar{r}_{t+1}} \\
c_{t}^{*}+a_{t+1}^{*} & =\bar{w}_{t} \epsilon_{t}\left(1-l_{t}^{*}\right)+\left(1+\bar{r}_{t}\right) a_{t}+\chi
\end{aligned}
$$

Now suppose we have a new economy with additional government debt issues $\Delta b$, a higher lump sum transfer in period 0 of $\chi_{0, \text { new }}=\chi+\Delta b$ and an additional lump sum tax $T_{t, \text { new }}=r_{t} \Delta b-\tau_{a} \Delta b=\bar{r}_{t} \Delta b$ for $t>0$.

Suppose each household saves exactly $\Delta b$ in addition: $a_{\text {new }, t+1}^{*}=a_{t+1}^{*}+\Delta b$, but chooses the same consumption and leisure path given the shocks and initial asset level. Clearly this satisfies the first two conditions above. It also satisfies the budget constraint of the household as we will show now. In period 0 :

$$
\begin{aligned}
c_{0}^{*}+a_{\text {new }, 1}^{*} & =\bar{w}_{0} \epsilon_{0}\left(1-l_{0}^{*}\right)+\left(1+\bar{r}_{0}\right) a_{0}+\chi_{0, \text { new }} \\
c_{0}^{*}+a_{1}^{*}+\Delta b & =\bar{w}_{0} \epsilon_{0}\left(1-l_{0}^{*}\right)+\left(1+\bar{r}_{0}\right) a_{0}+\chi+\Delta b
\end{aligned}
$$

In periods $t>0$ :

$$
\begin{aligned}
c_{t}^{*}+a_{\text {new }, t+1}^{*}+T_{t, \text { new }} & =\bar{w}_{t} \epsilon_{t}\left(1-l_{t}^{*}\right)+\left(1+\bar{r}_{t}\right) a_{\text {new }, t}+\chi \\
c_{t}^{*}+a_{t+1}^{*}+\left(1+\bar{r}_{t}\right) \Delta b & =\bar{w}_{t} \epsilon_{t}\left(1-l_{t}^{*}\right)+\left(1+\bar{r}_{t}\right)\left(a_{t}+\Delta b\right)+\chi
\end{aligned}
$$

As the households choose the same consumption and leisure the wage rate will be the same as in the old economy without government debt. As the savings of each individual household are higher by $\Delta b$ aggregate asset demand has to be higher by $\Delta b$ (households being a mass of one). Supply of assets is also higher by $\Delta b$ (closed economy) such that the interest rate in the economy will be the same. If we are in a stationary equilibrium in the initial economy, we will be in the same stationary equilibrium in the economy with government debt provided that it is financed with lump sum taxes and redistributed via lump sum transfers as shown above.

Finally it remains to show that such a policy satisfies the government budget given the same expenditure $G$, the same all time transfer $\chi$ and the same proportional taxes $\tau_{a}$ and $\tau_{l}$. In period 0 :

$$
\begin{gathered}
G+r_{0} B_{0}+T R_{0, \text { new }}=B_{1, \text { new }}-B_{0}+\tau_{l} w_{0} L_{0}+\bar{\tau}_{a} r_{0} \widehat{A}_{0} \\
G+r_{0} B_{0}+T R+\Delta b=B_{1}+\Delta b-B_{0}+\tau_{l} w_{0} L_{0}+\bar{\tau}_{a} r_{0} \widehat{A}_{0}
\end{gathered}
$$

In period $t>0$ :

$$
\begin{array}{r}
G+r_{t} B_{t, \text { new }}+T R=B_{t+1, \text { new }}-B_{t, \text { new }}+\tau_{l} w_{t} L_{t}+\bar{\tau}_{a} r_{t} \widehat{A}_{t, \text { new }}+T_{t, \text { new }} \\
G+r_{t}\left(B_{t}+\Delta b\right)+T R=B_{t+1}+\Delta b-B_{t}-\Delta b+\tau_{l} w_{t} L_{t}+\bar{\tau}_{a} r_{t}\left(\widehat{A}_{t}+\Delta b\right)+\left(1-\bar{\tau}_{a}\right) r_{t} \Delta b
\end{array}
$$


Thus we have shown that in the model with natural borrowing limits there is Ricardian equivalence. Suppose however we have instead an ad hoc borrowing limit which is binding for some households. In this case everything is the same except that for some agents savings are determined by $a^{\prime *}=\underline{a}$ and their Euler equation is not satisfied:

$$
\frac{\beta \sum_{\epsilon_{t+1}} \pi\left(\epsilon_{t+1} \mid \epsilon_{t}\right) u_{c}\left(c_{t+1}^{*}, l_{t+1}^{*}\right)}{u_{c}\left(c_{t}^{*}, l_{t}^{*}\right)}<\frac{1}{1+\bar{r}_{t+1}} \text { for agents with } a^{\prime *}=\underline{a}
$$

Now we can show by contradiction that Ricardian equivalence does not hold. Suppose Ricardian equivalence would hold, then the borrowing constrained households would have to save $a_{\text {new }}^{*}=\underline{a}+\Delta b$ and choose the same path for consumption and leisure. But if they choose the same path for consumption and leisure their Euler equation is still not satisfied, as shown by equation (8) above. But if the Euler equation doesn't hold for agents with $a_{n e w}^{\prime *}=\underline{a}+\Delta b$ it means they would like to go more into debt and they can do so as $a_{n e w}^{* *}=\underline{a}+\Delta b>\underline{a}$. Consequently they will not save $a_{n e w}^{*}=\underline{a}+\Delta b$. There is a contradiction. We have thus shown that Ricardian equivalence cannot hold in this case.

\section{Definition of the consumption equivalent welfare change}

The consumption equivalent welfare change for the average household is defined as the percentage change in consumption that the household must incur in the old situation in order to be indifferent between staying in the old stationary equilibrium and jumping to the new stationary equilibrium. Let the old stationary equilibrium be denoted by the subscript 0 and be characterized by a (detrended) debt level

$\tilde{b}_{0}=\frac{B_{0}}{Y_{0}}$ and a resulting density $\theta_{0}$. In our computations this point of comparison will always be the benchmark equilibrium with $\tilde{b}_{0}=\frac{2}{3}$. Let the new stationary equilibrium be denoted by the subscript 1 and characterized by the debt level $\tilde{b}_{1} \neq \tilde{b}_{0}$ and a resulting density $\theta_{1} \neq \theta_{0}$. The consumption equivalent welfare change for a household with assets $\tilde{a}$ and income state $\epsilon, x_{0 \rightarrow 1}$ is the percentage change in consumption in situation 0 that makes the household indifferent between staying in 0 and going to 1 :

$$
\begin{aligned}
& \int W\left(\tilde{a}, \epsilon ; \theta_{0}, x_{0 \rightarrow 1}\right) d \theta_{0}(\tilde{a}, \epsilon)=\int W\left(\tilde{a}, \epsilon ; \theta_{1}\right) d \theta_{1}(\tilde{a}, \epsilon) \\
& \int E_{0} \sum_{t=0}^{\infty} \tilde{\beta}^{t} \frac{\left(\left(c\left(\tilde{a}, \epsilon ; \theta_{0}\right) \cdot\left(1+x_{0 \rightarrow 1}\right)\right)^{\eta} l\left(\tilde{a}_{t}, \epsilon_{t} ; \theta_{0}\right)^{1-\eta}\right)^{1-\mu}}{1-\mu} d \theta_{0}(\tilde{a}, \epsilon)= \\
& \int E_{0} \sum_{t=0}^{\infty} \tilde{\beta}^{t} \frac{\left(c\left(\tilde{a}, \epsilon ; \theta_{1}\right)^{\eta} l\left(\tilde{a}, \epsilon ; \theta_{1}\right)^{1-\eta}\right)^{1-\mu}}{1-\mu} d \theta_{1}(\tilde{a}, \epsilon)
\end{aligned}
$$

Solving this equation for $x_{0 \rightarrow 1}$ we obtain:

$$
\begin{aligned}
x_{0 \rightarrow 1} & =\left(\frac{\int E_{t=0} \sum_{t=0}^{\infty} \tilde{\beta}^{t} \frac{\left(c\left(\tilde{a}, \epsilon ; \theta_{1}\right)^{\eta} l\left(\tilde{a}, \epsilon ; \theta_{1}\right)^{1-\eta}\right)^{1-\mu}}{1-\mu} d \theta_{1}(\tilde{a}, \epsilon)}{\int E_{t=0} \sum_{t=0}^{\infty} \tilde{\beta}^{t} \frac{\left(c\left(\tilde{a}, \epsilon ; \theta_{0}\right)^{\eta} l\left(\tilde{a}_{t}, \epsilon_{t} ; \theta_{0}\right)^{1-\eta}\right)^{1-\mu}}{1-\mu} d \theta_{0}(\tilde{a}, \epsilon)}\right)^{\frac{1}{\eta(1-\mu)}}-1 \\
& =\left(\frac{\int W\left(\tilde{a}, \epsilon ; \theta_{1}\right) d \theta_{1}(\tilde{a}, \epsilon)}{\int W\left(\tilde{a}, \epsilon ; \theta_{0}\right) d \theta_{0}(\tilde{a}, \epsilon)}\right)^{\frac{1}{\eta(1-\mu)}}-1
\end{aligned}
$$

Logically, if $x_{0 \rightarrow 1}$ is positive (negative) the average household would absent the compensation (not) prefer to be in the new situation. Thus a positive (negative) consumption equivalent welfare change means that the new debt level is (not) preferred in terms of welfare of the average household. 


\section{Numerical Algorithm}

The general algorithm to find the recursive general equilibrium is similar to Ábrahám and CárcelesPoveda (2010). Given a level of government debt, $b$, a tax rate for labor income, $\tau_{l}$, a tax rate for capital income, $\tau_{a}$ and a guess for the borrowing limit, $\underline{a}$, we search for the policy functions for consumption, leisure and next periods assets (savings), $c(),. l($.$) and a^{\prime}($.$) by using a policy function iteration method.$ More precisely, we use an endogenous grid point method, commonly used in the literature, which we extend to include endogenous labor. Then we compute the implied wealth density function using interpolation methods. Given the wealth densities we obtain a new equilibrium aggregate capital stock which implies a certain equilibrium interest rate and wage rate, as well as a new tax rate. Note that we either change the capital income tax or the labor income tax depending on the experiment. (Denote the respective tax rate simply as $\tau$ in what follows). Then we find the final equilibrium in two steps first iterating simultaneously over the aggregate capital stock and the tax rate we want to change and then in a further outer loop iterating over the borrowing limit (if endogenous). More precisely we take out the following steps to find the equilibrium given a certain level of government debt:

Loop to find borrowing limit Given a certain level of government debt, $b$, guess an initial vector for the borrowing limit $\underline{a}^{0}$. Denote iterations in this loop by $p$.

Loop to find interest rate and tax rate Denote iterations in this loop by $q$.

Step 1 Given a borrowing limit guess initial values for the tax rate, the aggregate labor supply and the aggregate capital stock: $\left[\tau^{0}, L^{0}, K^{0}\right]$. Those values for the aggregate capital stock and labor supply imply a certain interest rate $r^{0}$ and a certain wage rate $w^{0}$.

Step 2 Guess initial values for the policy functions $c^{0}(),. l^{0}(),. a^{\prime}($.$) . Now comes an inner loop$ to find the new policy functions. Denote iterations in this loop by $n$.

Step 3 For each iteration $n$ given $\left[w^{q-1}, r^{q-1}, \tau^{q-1}, \underline{a}^{p-1}\right]$ use the guesses, $\left[c^{n-1}(),. l^{n-1}(),. a^{\prime n-1}().\right]$ to compute new policy functions that satisfy the first order conditions of the households, $\left[c^{n}(),. l^{n}(),. a^{\prime}().\right]$.

Step 4 Find the associated density function over assets and income states.

Step 5 Given the density, compute the new aggregate capital stock $K^{q}$ and the new aggregate labor supply $L^{q}$, which imply a new wage rate $w^{q}$, a new interest rate $r^{q}$ and a new tax rate $\tau^{q}$. Then repeat Step 2-5 until we find the equilibrium interest rate, wage rate and tax rate given the guess for the borrowing limit.

Step 6 Use the policy functions at the final equilibrium to compute the value of autarky $V^{p}$ and the value of being in the financial market arrangement $W^{p}$, given the previous value for the borrowing limit $\underline{a}^{p-1}$.

Step 7 Compute the new borrowing limit, $\underline{a}^{p}$, by tightening them if $V^{p}>W^{p}$ and loosening them if $W^{p}>V^{p}$. Then repeat Step 1-7 until the equilibrium borrowing limit is found. 